\title{
Avaliação da fidelidade de troquéis de gesso obtidos de um poliéter (com a técnica do casquete) e confeccionados ou em diferentes momentos ou através de subseqüentes vazamentos num mesmo molde.
}

\section{Odirlei Arruda Malaspina}

Dissertação apresentada à Faculdade de Odontologia de Bauru, da Universidade de São Paulo, como parte dos requisitos para obtenção do título de Mestre em Odontologia, na área de Dentística, opção Materiais Dentários.

(Edição Revisada) 


\title{
Avaliação da fidelidade de troquéis de gesso obtidos de um poliéter (com a técnica do casquete) e confeccionados ou em diferentes momentos ou através de subseqüentes vazamentos num mesmo molde.
}

\section{Odirlei Arruda Malaspina}

\begin{abstract}
Dissertação apresentada à Faculdade de
Odontologia de Bauru, da Universidade de São Paulo, como parte dos requisitos para obtenção do título de Mestre em Odontologia, na área de Dentística, opção Materiais Dentários.
\end{abstract}

(Edição Revisada)

Orientador: Prof. Dr. César Antunes de Freitas

Bauru

2005 


\section{Malaspina, Odirlei Arruda}

M291a Avaliação da fidelidade de troquéis de gesso obtidos de um poliéter (com a técnica do casquete) e confeccionados ou em diferentes momentos ou através de subseqüentes vazamentos num mesmo molde./ Odirlei Arruda Malaspina. - Bauru, 2005.

75p.; 15 il.; $30 \mathrm{~cm}$.

Dissertação (Mestrado) - Faculdade de Odontologia de Bauru, Universidade de São Paulo.

Orientador: Prof. Dr. César Antunes de Freitas.

Autorizo, exclusivamente para fins acadêmicos e científicos, a reprodução total ou parcial desta dissertação, por processos fotocopiadores e outros meios eletrônicos.

Assinatura:

Data: 26/04/2005 


\title{
Odirlei Arruda Malaspina
}

\author{
DADOS CURRICULARES
}

$16 / 03 / 1979$

$1997-2000$

$2001-2002$

$2001-2003$

$2003-2005$
Nascimento em Sorocaba-SP, filho de Ovídio Malaspina e Mércia Maria Dias de Arruda Malaspina.

Curso de graduação em Odontologia pela Faculdade de Odontologia de Bauru -

Universidade de São Paulo (FOB-USP).

Especialização em Radiologia pela Associação Paulista de Cirurgiões Dentistas (APCD) regional Bauru.

Treinamento no setor Clínico e de Pesquisas realizado junto ao Departamento de Dentística, Endodontia e Materiais Dentário da Faculdade de Odontologia de Bauru - Universidade de São Paulo sob a supervisão do Prof. Dr. José Mondelli.

Curso de Pós-graduação (Mestrado),na área de Dentística, opção Materiais Dentários, pela Faculdade de Odontologia de Bauru (FOB-USP). 


\section{Dedicatóría}

Ao Grande Arquiteto

À Nossa Senhora Aparecida

Ao meu pai Ovídio Malaspina (em memória)

À minha mãe Mércia Maria Dias de Arruda Malaspina

A minha irmã Érica Arruda Malaspina 
"Se eu pude ver mais longe, é porque estava me apoiando sobre os ombros de gigantes" 


\section{Agradecimentos Especiais}

Agradeço imensamente ao Prof. Dr. José Mondelli por me apresentar os caminhos de magistério e da pesquisa.

Ao meu amigo Prof. Dr. César Antunes de Freitas por sua ilimitada ajuda e orientação na confecção e redação deste trabalho.

A minha namorada Tatiana por me alegrar nas horas difíceis, compartilhar os momentos alegres, pela compreensão, companheirismo e incentivo irrestrito e inestimável.

A minha segunda família Wilson, Alice e Thiago pelo acolhimento e pela torcida constante.

Ao meu amigo Prof. Dr. Marcelo Agnoletti Pereira por compartilhar seus conhecimentos e sua amizade.

Ao meu amigo e parceiro de clínica, durante o curso de graduação e pós-gradução, Adilson Yoshio Furuse, porque grandes tarefas se tornam mais fáceis quando realizadas em duplas.

Ao meu professor Mário Kodama por me apresentar aos mistérios do universo, às teorias de conspiração, à pureza e à simplicidade da física e a sua amizade.

Aos meus amigos Carlos, Emir, Fernando, José Eduardo, Leandro, Tiago, Vinicius e ao Ming Li por serem "simplesmente amigos”. 


\section{Agradecimentos}

À Faculdade de Odontologia de Bauru da Universidade de São Paulo, na pessoa de sua Diretora Prof. Dra. Maria Fidela de Lima Navarro e do coordenador da PósGraduação Prof. Dr. José Carlos Perreira.

Aos Professores da Disciplina de Materiais Dentários da Faculdade de Odontologia de Bauru-USP, Profs. Drs. Paulo Afonso Silveira Francisconi e Paulo Amarante de Araújo.

Aos Professores da Disciplina de Dentística da Faculdade de Odontologia de BauruUSP.

Aos Prof. Dr. José Roberto Pereira Lauris, da Disciplina de Odontologia Social da Faculdade de Odontologia de Bauru-USP.

Aos meus colegas da pós-graduação, Anderson, Carla Giannini, Carla Porto, Luísa, Renato, Rosa, Rosana, Sérgio e a Vera.

Aos funcionários da Disciplina de Materiais Dentários da Faculdade de Odontologia de Bauru-USP: Alcides, Sandra e Lourisvalda. 
Aos funcionários da Biblioteca da Faculdade de Odontologia de Bauru-USP.

Ao Governo do estado de São Paulo, na pessoa de seu Governador Geraldo Alckmin por proporcionar a minha graduação e pós-graduação.

Ao CNPq, por fomentar minha pesquisa nos últimos 10 meses. 


\section{Sumário}

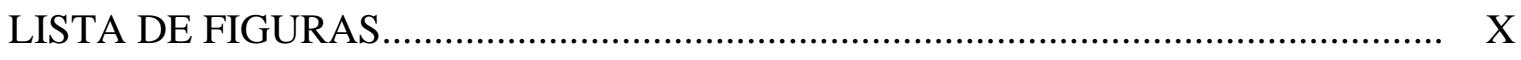

LISTA DE TABELAS................................................................................... XI

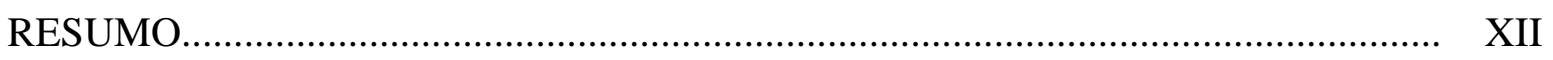

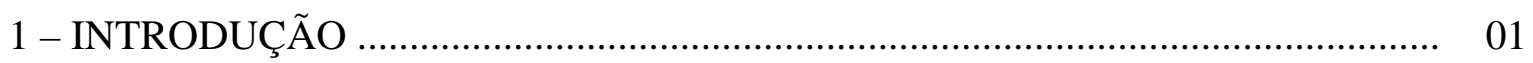

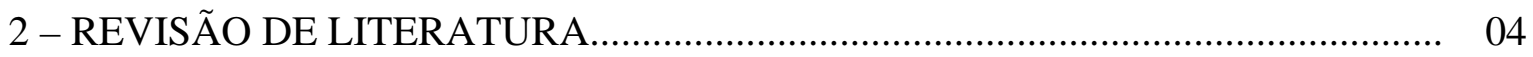

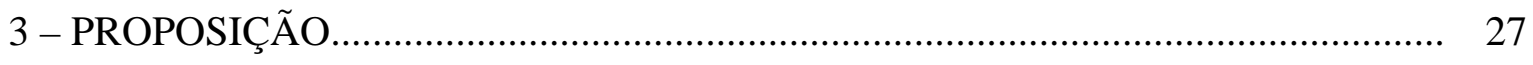

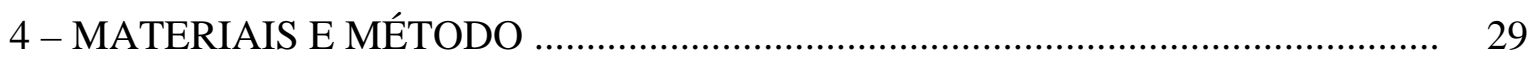

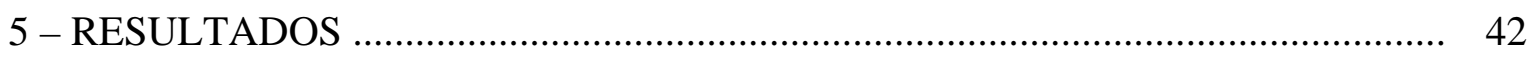

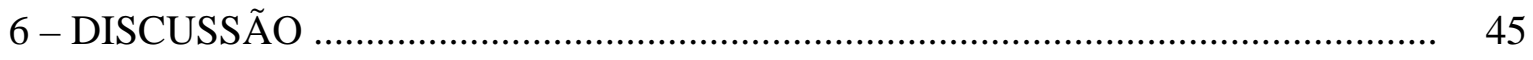

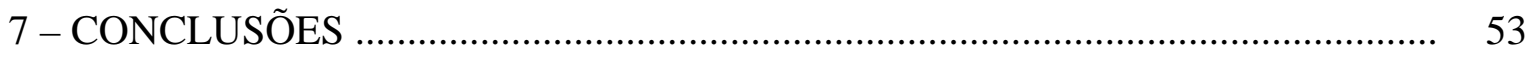

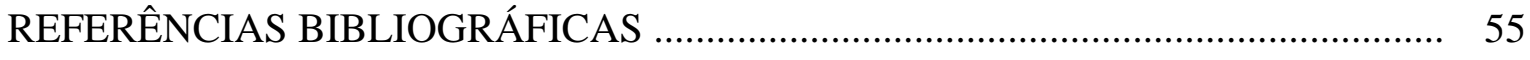

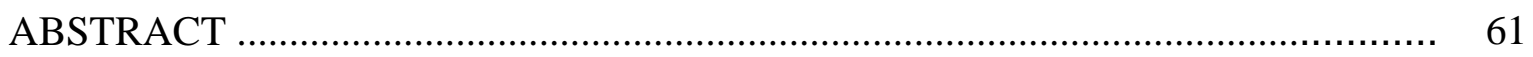




\section{Lista de Figuras}

FIGURA 1- Esquema (modificado do original de Marchese ${ }^{22}$ ) do troquel-padrão, com suas distâncias expressas em milímetros e seus ângulos em graus.

FIGURA 2- Esquema (modificado do original de Marchese $^{22}$ ) do dispositivo de moldagem utilizado. As letras e siglas identificam as partes descritas no texto: B - base; PM - parte móvel ou braço; HV - haste vertical; M moldeira; PFM - parafuso fixador da moldeira; T - troquel-padrão ; PFT - parafuso fixador do troquel-padrão; CAFT - cilindro auxiliar de fixação do troquel-padrão; AMA - anel de manutenção de altura da parte móvel; AE - anel espaçador e CC - cilindro centralizador

FIGURA 3- Troquel-padrão com a coroa-padrão..................................................... 40

FIGURA 4- Foto do dispostivo de medição............................................................... 40

FIGURA 5- Casquete de resina, com espaçador ainda dentro...................................... 40

FIGURA 6- Casquete em posição no dispositivo de moldagem.................................... 40

FIGURA 7- Casquete em posição sem o braço do dispositivo de moldagem................ 40

FIGURA 8- Momento da remoção do espaçador de dentro de um casquete.................. 40

FIGURA 9- Adesivo sendo aplicado num casquete................................................... 41

FIGURA 10- Casquete, preenchendo-o com grande excesso...................................... 41

FIGURA 11- Escoamento do material de moldagem.................................................. 41

FIGURA 12- Formação do colarinho ao redor da base do troquel-padrão...................... 41

FIGURA 13- Colocação de uma tira de poliéster embaixo da ponta ativa do micrômetro................................................................................. 41

GRÁFICO 1 - Ilustrativo da tabela 1, com valores expressos em micrometros............ 44 


\section{Lista de Tabelas}

TABELA 1- Valores individuais (em micrometros) da adaptação da coroa-padrão em cada troquel de gesso, para cada uma das cinco condições já descritas, com sua média (m), seu desvio-padrão (dp) e seu coeficiente de variação (cv) 
Resumo 


\section{Resumo}

Avaliou-se, indiretamente, a fidelidade de moldes tomados (pela técnica do casquete) com o poliéter Impregum Soft, verificando-se a diferença de altura existente entre uma coroa-padrão e os respectivos troquéis de gesso Vel-Mix, obtidos utilizando-se o molde uma única vez, ou mais de uma, em diferentes idades, compondo-se assim os 5 seguintes grupos: R0/U0 - vazamento único, imediato; U1 - vazamento único, após 1 hora; U2 - vazamento único, após 2 horas; R1 - segundo vazamento, após 1 hora, e R2 - terceiro vazamento, após 2 horas. O resultado ideal seria que não houvesse diferença de altura, na porção oclusal, entre a coroa-padrão e cada troquel de gesso no qual aquela fosse adaptada. A análise estatística dos valores de desajuste detectados permitiu concluir que: 1 - Em todos os grupos, os troquéis apresentaram-se sempre maiores do que a estrutura original; 2 - O melhor resultado foi apresentado pelos troquéis dos grupos R0/U0 e U1, onde os desajustes foram respectivamente de 80,75 e 114,25 micrometros; 3 - Nos grupos R1 e R2, os desajustes foram semelhantes entre si (porém piores que os dos grupos R0/U0 e U1), com desajustes respectivamente de 153,98 e 184,54 micrometros, e 4 - Os piores resultados foram observados no grupo U2, no qual o desajuste foi de 323,36 micrometros. 
Introdução 


\section{1- Introdução}

Em Odontologia, há casos onde é necessário reproduzir a arcada dentária de pacientes, de forma total ou parcial, com a finalidade de confeccionar elementos protéticos, ocasião onde deve existir a maior precisão possível.

Buscando confeccionar-se peças protéticas que possam restaurar as qualidades de um dente, entre elas a função, o processo mais rotineiramente empregado utiliza modelo de gesso (denominado troquel quando referente a apenas um único dente) obtido a partir de um molde tomado do dente preparado, essa última expressão querendo descrever que o remanescente dentário sofreu algum tipo de desgaste.

Dentre o grande número de fatores que influenciam a justeza destas peças (adaptando-se bem ao troquel e, conseqüentemente, ao remanescente dentário) podem ser citadas, as propriedades do material de moldagem e o tempo de demora para o vazamento do gesso no molde.

Sabe-se que os elastômeros são os materiais de moldagem mais utilizados atualmente neste processo, podendo pertencer a um dos seguintes grupos químicos: do polissulfeto, das siliconas (com dois sub-grupos, dependentes do tipo de polimerização, por condensação ou por adição) e do poliéter.

Dentre as técnicas de moldagem empregadas com estes materiais encontra-se a do casquete, o qual é basicamente uma moldeira, confeccionada em resina acrílica geralmente autopolimerizável, que servirá para um único dente.

Teoricamente, usar um casquete implica na possibilidade não apenas de existir um menor gasto de material, mas principalmente no fato da camada do material de moldagem, futuramente utilizado no seu interior, ter menor espessura, assim minimizando o problema da contração de polimerização deste e consequentemente conduzindo à obtenção de moldes mais exatos, que farão resultar troquéis mais exatos.

Ainda é necessário pesquisar se existem conseqüências negativas causadas pela demora do vazamento do gesso no molde de elastômero (como rotineiramente é feito por muitos dentistas), ou pela confecção de sucessivos modelos, dentro de um 
mesmo molde (prática também rotineiramente desenvolvida por vários dentistas), quanto à precisão dos respectivos troquéis obtidos. 
Revisão da literatura 


\section{2- Revisão da Literatura}

Em 1953, $\mathbf{L E F F}^{20}$ apresentou uma técnica, por ele idealizada, a qual considerou ser simples e rápida, para construir coroas provisórias, em acrílico, no caso de dentes preparados para receber os diferentes tipos de coroas. Em linhas gerais, um primeiro molde de alginato era tomado da região onde se encontrava o dente a ser restaurado; no respectivo modelo de gesso, o remanescente dentário em foco era reconstruído com cera, ocasião em que um segundo molde de alginato era obtido; usando este último molde como uma matriz, dentro da cavidade correspondente ao referido dente, era depositada, usando-se a conhecida técnica do pincel, uma fina camada de resina acrílica ativada quimicamente, também conhecida pela sigla RAAQ; após polimerizada, a peça resultante (uma espécie de capa) era preenchida com outra porção daquela mesma resina e devidamente pressionado no remanescente dentário preparado, tarefa esta efetuada com o material no estado fluido, ocasião na qual solicitava-se ao paciente para "morder sobre o provisório", visando-se assim "estabelecer a oclusão”; as franjas de material (excessos) oriundas de tal operação eram aparadas e a coroa provisória, depois de polida e reajustada quanto à oclusão, estaria pronta para ser cimentada. Esta técnica apresentaria, segundo seu idealizador, vantagens sobre uma outra então existente, inclusive por necessitar de uma quantidade mínima de ajuste oclusal e de não ser necessário "mutilar ou destruir" o modelo de gesso. O referido pesquisador ainda discutiu uma série de variações dos procedimentos técnicos acima descritos.

Em 1955, BAILEY ${ }^{5}$, procurando melhorar a qualidade dos modelos de gessos, construídos a partir de moldes obtidos com materiais "à base de borracha”, apresentou uma técnica de moldagem (em casos de ponte-fixa e de coroas isoladas) que utilizava moldeiras individuais confeccionadas em resina acrílica. Em um modelo de gesso, a área a ser abrangida pela futura moldeira era coberta com uma camada de cera, com aproximadamente 1 à 1,5 mm de espessura, com o objetivo de eliminar as áreas retentivas e de reservar o espaço necessário para o futuro material de moldagem. Assim, a RAAQ era aplicada 
no modelo, sobre a cera, de tal sorte que a moldeira ganhava a forma adequada; “endurecida” a resina, a moldeira era então removida do modelo e nela eram feitos furos, para assim prover a retenção do respectivo material de moldagem. A “boa qualidade” dos moldes assim obtidos, segundo o referido autor, podia ser atribuída à boa adaptação das moldeiras individuais e à boa qualidade de impressão do material utilizado.

Em 1965, CANNISTRACI ${ }^{9}$ descreveu, de forma detalhada, uma técnica para confecção de moldeiras individuais, em resina acrílica, usando um método que combinava, nos padrões da época, “as vantagens da técnica dos anéis de cobre e a dos hidrocolóides reversíveis”, o que proporcionava "retração dos tecidos moles e consumia um tempo menor do que aquele empregado na técnica dos anéis de cobre”. Tal técnica (modificação de uma outra, desenvolvida por $\mathbf{L E F F}^{20}$, para construção de coroas acrílicas provisórias) consistia em se tomar um molde de alginato e aplicar-se, com o auxilio de um pincel, uma fina camada de resina acrílica, nas cavidade referentes aos remanescentes dentários de interesse, de tal sorte a se obter uma pequena casca (casquete), a qual se esperava polimerizar; cada casca polimerizada era removida do molde, preenchida com nova porção de resina acrílica e pressionada ainda fluida sobre o dente previamente preparado; após a polimerização desta última porção de resina, removia-se os excessos marginais provenientes de tal operação, juntamente com cerca de $1 \mathrm{~mm}$ da porção interna da peça, para que esta fosse transformada em uma moldeira; um adesivo era aplicado nas faces internas e externas desta moldeira, aguardando-se sua secagem por 2 minutos; com o auxilio de uma seringa, preenchia-se a moldeira com o respectivo elastômero e se realizava a moldagem. $\mathrm{O}$ autor assim se expressou: "Há muita controvérsia sobre quanto tempo exatamente um molde de elastômero pode aguardar, antes de ser preenchido. Não há dúvidas de que quanto antes tal procedimento seja efetuado, menor será a possibilidade de alteração dimensional. Porém, eu não encontrei alterações clinicamente significantes por um período de até 24 horas”. Entretanto, não mencionou nada sobre quais foram os testes usados por ele, que permitiram fazer tais afirmações. 
Em 1969, TOSTI ${ }^{35}$, procurando melhorar a precisão e facilitar a confecção dos modelos de gesso, descreveu, passo-a-passo, uma técnica de fabricação de moldeiras acrílicas, construídas diretamente na boca do paciente, englobando vários dentes, inclusive aqueles preparados para receber coroa protética. Uma porção de resina acrílica, na fase plástica, era comprimida sobre os dentes envolvidos; dela, após a polimerização ter ocorrido, eram removidos os excessos, as porções retentivas e 2-3 milímetros da área interna referente a cada dente preparado, criando-se assim um espaço destinado a acomodar o material de moldagem; após a secagem do adesivo e com a moldeira preenchida com o material “de corpo pesado”, realizava-se uma primeira moldagem; obtido este molde, o processo de moldagem era repetido, agora com o material “de corpo leve”, para que ocorresse, em sua opinião, uma melhor reprodução “da extensão sub-gengival do preparo”. Dentre as vantagens por ele mencionadas, o autor destacou a boa precisão do molde, em conseqüência da pequena espessura do material de moldagem.

Em 1970, STACKHOUSE $\mathbf{J r}^{33}$ avaliou a precisão de troquéis de 1 gesso (Vel Mix), obtidos de uma 1 mercaptana (Permlastic) e 3 siliconas (Plastosil, Elasticon e Lastic ), influenciados pela técnica de moldagem e pelo tempo de espera em se vazar gesso no molde. Para tanto, usou cinco troquéis originais (todos confeccionados em aço) e 3 diferentes técnicas de moldagem, uma primeira, denominada do espaço de reserva (na qual o material “de corpo pesado” era pressionado contra troquéis-mestres, os quais encontravam-se cobertos com capas que reservavam o espaço para o material leve), uma segunda, denominada da moldeira perfurada (condição na qual o excesso de material de moldagem poderia extravasar livremente) e uma terceira, denominada da duas misturas usadas simultaneamente. O efeito da demora em se vazar o gesso nos moldes foi avaliado através da observação das diferenças geométricas encontradas entre os troquéis obtidos nos intervalos de 1/2, 11/2 e 21/2 horas após o molde ser tomado. As medidas dos troquéis (altura e largura) foram efetuadas por meio de um microscópio de medição. O autor concluiu que “as siliconas produziram espécimes de precisão mais uniforme que a mercaptana”, que "uma das siliconas era significantemente diferente das outras 
duas”, que existe diferenças entre as técnicas de moldagens, que a demora em se vazar o gesso promoveu "o aparecimento de modelos menores em altura, mas com diâmetros maiores”, o que piorava a precisão do molde, e que "sucessivos vazamentos, num mesmo molde, implicaram em alterações dimensionais dos troquéis de gesso, acima dos níveis estabelecidos na Especificação $\mathrm{n}^{0} 19$ da American Dental Association (ADA ${ }^{1}$ )”, os quais estavam então em vigor.

Em 1971, $\mathbf{A S G A R}^{4}$ publicou uma série de conclusões provenientes de um então recente Simpósio acerca dos materiais de moldagem mais usados na época. Destacou que todos os elastômeros sofriam contração de polimerização (cuja intensidade porém era dependente do método e da forma de avaliação), que a espessura da sua camada influía na fidelidade dos modelos, que cada material tem características próprias (e portanto problemas inerentes a cada um), que o vazamento do gesso nos moldes dentro de no máximo 30 minutos reduziria a quantia de distorções e que caberia aos profissionais ter os cuidados necessários durante todos os passos da tomada do molde, para que pudessem ser minimizadas as distorções inerentes a cada técnica e material.

Ainda em 1971, CALOMENI ${ }^{8}$, procurando melhorar a qualidade dos moldes obtidos pela técnica do reembasamento, descreveu uma técnica simplificada onde era tomado um molde em alginato da área de interesse e sobre o modelo obtido acrescia-se de 3 a 4 milímetros de cera, criando um maior espaço para o material de moldagem; assim, confeccionava-se, em resina acrílica autopolimerizável, uma moldeira parcial a qual era provada na boca do paciente e ajustada, evitando compressão dos tecidos moles, após esta ser removida e seca era aplicado o adesivo de moldeira e esperava-se sua secagem por 10 minutos antes de seu preenchimento com o elastômero pesado; depois de tomado o molde era realizado alívios nas regiões retentivas e cortes na forma de V; na região dos dentes preparados era aplicado o elastômero leve, e a moldeira era novamente levada em posição até a polimerização do material. Segundo o autor, algumas das vantagens desta técnica seriam: a maior reprodução de detalhes da área moldada, a diminuição do aparecimento de bolhas nas partes criticas do molde, um adequado tempo de trabalho, era 
necessária uma mínima contração dos tecidos gengivais, haveria uma camada uniforme de material de moldagem presente na impressão final e a polimerização ocorreria em uma taxa uniforme.

Em 1972, BRADEN, CAUSTON \& CLARKE ${ }^{7}$, procurando avaliar um novo material de moldagem (o poliéter), publicaram um bem estruturado estudo sobre a composição química e as características físicas deste "recém criado” elastômero. Para tanto, avaliaram a composição química, a reologia da pasta base, o tempo de polimerização, a absorção de água, a alteração dimensional, a expansão térmica e as propriedades viscoelásticas do material. Após os testes concluíram que: a ligação cruzada existente no poliéter é feita por um sulfonato aromático, o material é de fácil manipulação, inodoro e de polimerização mais rápida que os polissulfetos; a pasta base exibe viscosidade não-newtoniana, um alto módulo de elasticidade e uma moderada a resistência ao rasgamento; apresenta boa estabilidade dimensional em ar, porém tem alta afinidade pela água, o que afeta a estabilidade dimensional pela sorção e pela dissolução de componentes solúveis quando em contato direto, sendo esta a principal desvantagem do material; a expansão térmica é maior para os poliéteres do que para outros elastômeros, sendo a causa mais provável o fato dos poliéteres possuírem uma baixa carga orgânica.

Em 1975, BELL \& VON FRAUNHOFER ${ }^{6}$ publicaram uma revisão de literatura sobre a acuidade dos elastômeros de moldagem (siliconas, poliéteres e polissulfetos); foram abordados o “desenvolvimento”, a “química”, os "efeitos da contração do material, moldeiras individuais e adesivos”, a “precisão e estabilidade”, técnicas de moldagem, revazamento de molde e os efeitos da umidade. Por fim, durante a conclusão, foram feitas uma série de recomendações sobre o uso dos elastômeros para se obter a "máxima precisão dos moldes”, tais como aumentar em 50\%, para todos os materiais, o tempo de presa recomendado pelos fabricantes; as moldeiras individuais seriam preferíveis às de estoque, devendo ser utilizadas sempre que possível, pois permitiriam a existência de uma espessura o mais uniforme possível do material de impressão no seu interior, parecendo ser ótima uma espessura entre 2 a $4 \mathrm{~mm}$; idealmente o molde deveria aguardar 30 minutos para ser vazado 
com gesso para que pudesse ocorrer a recuperação elástica do material; parecia haver pouca diferença entre as técnicas da dupla mistura e a do reembasamento, desde que sulcos de escape fossem confeccionados nesta última; os troquéis obtidos através de um segundo vazamento do gesso, dentro de um mesmo molde, seriam sempre menos precisos do que os primeiros, independentemente da técnica de moldagem, e deveriam ser utilizados apenas para fins de posicionamento, enquanto que as margens de eventuais coroas deveriam ser sempre ajustadas no primeiro destes troquéis; a umidade relativa ambiental e a contaminação com água afetaria a presa do material de moldagem acelerando-a; a umidade ambiental afetaria também o material já polimerizado, e seria um fator de grande importância na precisão dos troquéis, principalmente se o molde esperasse muito tampo até ser vazado; em condições de alta umidade relativa ambiental, os polissulfetos pareciam ser os materiais de escolha; os moldes de poliéteres nunca deveriam ser mantidos em condições de alta umidade ambiental, nem dentro de sacos hermeticamente fechados, nem junto com moldes de alginato; e finalmente a manutenção dos moldes de siliconas, em condição “de umidade”, pareceu prevenir a perda de componentes voláteis, enquanto a contração de polimerização pareceu ter sido compensada pela absorção de água, apesar do fato de que; para as siliconas, a perda de precisão seria promovida tanto por condições de alta como de baixa umidade.

Em 1977, a entidade American Dental Association ${ }^{1}$ publicou uma revisão da sua Especificação $n^{0} 19$, que trata sobre materiais odontológicos de impressão elastoméricos não aquosos. A citada Especificação para os elastômeros toma como base polissulfetos, polivinilsiloxanos, poliéteres e outros materiais não aquosos, capazes de reagir e formar um material semelhante à borracha, podendo ser usados para se fazer impressões; desta forma, os elastômeros foram classificados de acordo com suas propriedades elásticas e suas alterações dimensionais, após a polimerização, em tipo I, II e III, onde cada tipo é ainda classificado de acordo com seu uso e sua viscosidade aparente. São apresentadas as definições para o "tempo de mistura” (aquele requerido para se obter uma coloração uniforme e homogênea 
dos componentes), "tempo de trabalho" (contado a partir do início da mistura até a viscosidade não mais permitir fazer impressões) e "tempo de polimerização” (medido a partir do início da mistura, quando as propriedades plásticas permitem fazer impressões, até o momento em que estas propriedades sejam perdidas e as propriedades elásticas do material permitam que este seja removido das áreas retentivas). A seguir são apresentados as "especificações aplicáveis”, os “requisitos”, as “amostras, inspeções e procedimentos para teste”, a forma de apresentação e as notas finais. Neste ultimo tópico são tratados alguns aspectos que não fazem parte das normas, como a "toxicidade", a "liberação de gases”, “compatibilidade com os gessos”, “informação sobre equipamento e procedimento de teste”, "bloco de teste rígido e equipamentos auxiliares” e "Fatores de conversão".

Em 1978, VALLE ${ }^{37}$ analisou através do desajuste cervical de coroas metálicas fundidas em liga áurea, o comportamento de 3 tipos de elastômeros (uma mercaptana o Unilastic; uma silicona de condensação e um poliéter o Impregum) quando empregados com a técnica do casquete e da moldeira individual acrílica que proporcionavam, respectivamente, 0,5 e $3 \mathrm{~mm}$ de espessura para os diferentes materiais de moldagem. Dois troquéis metálicos, um esquemático e outro que simulava um preparo clínico, foram moldados e vazados em gesso especial, obtendo-se em seguida o padrão de cera e a fundição das coroas totais. Afirmou ter observado que “o uso do casquete individual resultou em desajuste acentuadamente menor do que com a moldeira individual”; “com a técnica da moldeira individual, o poliéter apresentou o melhor comportamento, seguido da silicona e da mercaptana” e que "com a técnica do casquete individual, o poliéter apresentou o melhor comportamento, seguido da mercaptana, com resultados semelhantes entre si.

Em 1979, EAMES et al. $^{15}$ investigaram a influência do volume dos elastômeros, entre o dente preparado e a moldeira, sobre a precisão dos moldes para 3 polissulfetos, 2 poliéteres e 2 siliconas, para isso utilizaram um troquel de aço inoxidável que apresentava uma inclinação de 12 graus de expulsividade em suas paredes circundantes simulando um dente preparado; para a padronizar as espessuras do material de moldagem no interior das 
moldeiras, foi utilizado um equipamento de moldagem a vácuo onde foram construídas as moldeiras em material plástico e assim reservado um espaço de 2, 4 ou $6 \mathrm{~mm}$ para o material de moldagem. Foram confeccionados 15 espécimes (5 para cada espessura) de cada um dos materiais, a polimerização ocorria com o conjunto (troquel, moldeira e elastômero) imerso em água a $37^{\circ}$ C. Estes espécimes eram submetidos a leitura de suas alterações dimensionais com 30 minutos e 24 horas de idade através da medição das distâncias entre as linhas impressas no molde; estas medidas, como todas as outras medidas realizadas neste trabalho, foram feitas com auxílio de um microscópio de leitura linear com acuidade de 5 micrometros. Para simular uma aplicação clinica, foram escolhidos 3 materiais (o Polyjel, o Omniflex e o Permlastic) e feitos mais 9 espécimes (3 de cada espessura), e preenchidos imediatamente com gesso Vel-Mix. Foram encerados copings diretamente sobre o troquel de aço e fundidos. Em seguida, foram assentados sobre os troquéis e o nível de adaptação entre ambos foi verificado com a medição da fenda presente na região cervical. Os autores relataram ter observado que a espessura de $2 \mathrm{~mm}$ promoveu melhor precisão do que as de 4 e $6 \mathrm{~mm}$, sendo que, com essas duas últimas espessuras, a desadaptação das peças obtidas não seria aceitável clinicamente.

Novamente em 1979, EAMES et al. ${ }^{16}$ publicaram outro trabalho na mesma linha de pesquisa, porém, testando 34 materiais de 13 diferentes fabricantes quando a precisão de moldagem e estabilidade dimensional. Para isso 10 espécimes de cada material foram confeccionados seguindo a Especificação ${ }^{0} 19$ da $\mathbf{A D A}^{1}$ e os espécimes avaliados com 30 minutos e 24 horas de vida, com o auxílio de um microscópio de leitura linear, quanto a suas mudanças dimensionais. Adicionalmente, 20 "sistemas de impressões” foram utilizados simulando seu uso clínico; para tanto, uma matriz de aço inoxidável com as mesmas características da utilizada no trabalho anterior foi moldada; utilizando uma moldeira plástica padronizada com espaço interno de 2,4 mm, os moldes assim obtidos foram vazados com gesso na idade de 30 minutos e 24 horas. Para avaliar a precisão dos troqueis, foram encerados copings diretamente sobre o troquel de aço e fundidos. Em seguida, estes foram 
assentados sobre os troquéis e o nível de adaptação entre ambos foi verificado com a medição da fenda presente na região cervical Os autores observaram que a contração de todos os materiais aos 30 minutos variou entre $0,11 \%$ e $0,45 \%$, e com 24 horas entre $0,18 \%$ e $0,84 \%$. Os poliéteres e os polissulfetos, em geral, foram os mais estáveis e as siliconas de condensação as menos estáveis. As novas siliconas de adição exibiram as menores alterações, com equivalência estatística aos poliéteres; e relataram ter concluído que “é amplamente aceito que os moldes deveriam ser vazados com gesso o quanto antes possível e que quando vazados com gesso imediatamente, muitos dos materiais avaliados exibiram características de estabilidade similares e os dentistas poderiam basear suas escolhas em outros aspectos” e “em situações que impedem o vazamento imediato do gesso, apenas os materiais mais estáveis deveriam ser utilizados”.

Ainda em 1979, NAYYAR et al. $^{25}$ publicaram um trabalho comparando um poliéter, o Polyjel, com um polissulfeto, o Permlastic, quanto ao tempo de trabalho, tempo de presa e limite elástico. O teste de "tempo de trabalho" foi avaliado de 3 formas: seguindo a Especificação n ${ }^{0} 19$ da $\mathbf{A D A}^{1}$; com um teste “clinico” onde 5 dentistas recebiam uma seringa, contendo um dos materiais, e respondiam se este estava bom para uso; e através de um reômetro desenvolvido por H.J. Wilson que possibilitava controlar a temperatura das amostras durante os testes. O teste de "tempo de presa" foi realizado de duas formas: usando o mesmo reômetro de Wilson; e com um teste "clínico" (o qual não foi descrito) realizado por 5 dentistas. O 'limite elástico” foi avaliado para ambos materiais segundo a Especificação $n^{0} 19$ da $\mathbf{A D A}^{1}$, porém esta não apresenta nenhuma normatização para a realização do teste de "tempo de presa" e como o teste de "limite elástico" pede que o tempo de presa do material fosse respeitado, os autores decidiram utilizar 5 tempos com intervalos de 60 segundos entre eles, sendo o primeiro tempo baseado nos resultados encontrados pelos próprios autores em seus testes. Os autores concluíram que: o tempo de trabalho recomendado pelos fabricantes, para o poliéter, é aproximadamente 40 segundo maior que aquele encontrado nos testes clínicos e no da $\mathbf{A D A} \mathbf{A}^{1}$; se um maior tempo de trabalho é desejado, deve-se usar o 
polissulfeto; e este é mais sensível a mudanças de temperaturas que o poliéter; se for aguardado um tempo maior antes de se remover o molde, a distorção de remoção do molde será menor; para os poliéter um acréscimo de 2 minutos no tempo de espera para se desmoldar reduz significantemente a distorção de remoção do molde.

Em 1980, MARCINAK et al. $^{24}$, por acreditarem que a alteração dimensional em moldes decorrente da demora em se vazar gesso sobre eles era um dos principais fatores que influenciariam a precisão dos mesmos, publicaram um estudo sobre o tema avaliando 4 polissulfetos, 2 siliconas, 1 poliéter e 1 hidrocolóide reversível quanto a influencia da idade do molde no momento do vazamento deste. Dois incisivos centrais foram montados em um bloco acrílico, simulando seu posicionamento original no arco dentário, e feito um enceramento com $3 \mathrm{~mm}$ de espessura sobre eles, foi tomada uma moldagem e sobre o modelo confeccionadas moldeiras. Para obtenção do modelo padrão de moldagem, os incisivos centrais tiveram sua porção incisodistal desgastadas de forma a ficarem paralelas; as impressões para os polissulfetos e o poliéter usaram uma moldeira individualizada e as siliconas moldeiras perfuras e técnica da dupla mistura. Foram feitas 18 moldagens (3 para cada tempo) para cada um dos materiais, elas foram realizadas a $37^{\circ} \mathrm{C}$ e $100 \%$ de umidade relativa do ar; os moldes assim obtidos foram vazados com idade de 5 minutos, 30 minutos, 1 hora, 2 horas, 8 horas e 24 horas; a precisão dos modelos foi avaliada pela medição da distância criada entre as superfícies paralelas na porção distal dos incisivos centrais por um micrômetro com acuidade de $\pm 0,0025$ milímetros. Os autores relatam ter concluído que os polissulfetos produzem troquéis maiores que o padrão original quando vazados dentro de 24 horas, as siliconas produzem troquéis menores com o passar do tempo, o poliéter produz um troquel menor se vazado até 8 horas e maior se vazado entre 8 e 24 horas, o hidrocolóide reversível se mostra preciso se vazado até 30 minutos, mas decorrido este tempo apresenta uma rápida perda de precisão gerando troquéis menores que o padrão original.

Em 1981, CIESCO et al. ${ }^{12}$ compararam a estabilidade dimensional e a precisão de alguns materiais “à base de borracha” em diferentes intervalos de 
tempo. Usaram neste trabalho 2 polissulfetos, 2 siliconas ( uma de condensação e outra de adição), todos esses materiais possuíam consistência fluida e 1 poliéter que só é fabricado na consistência média. Foram empregadas duas técnicas de moldagem: uma que usava uma moldeira individual e um adesivo, e outra que empregava uma moldeira de estoque. Afirmaram que todos os materiais, cujos moldes foram vazados imediatamente e que foram confeccionados com auxílio de uma moldeira individual com adesivo, apresentaram melhores resultados quando comparados àqueles obtidos com moldeiras de estoque, e que a silicona de adição apresentou melhores resultados do que o polissulfeto e a silicona de condensação.

Também em 1981, LANCY et al. $^{19}$ compararam a precisão e a estabilidade dimensional alguns elastômeros (1 poliéter, 4 polissulfetos e 4 siliconas de adição), verificando a magnitude da mudança no tamanho de modelos obtidos em vazamentos seqüenciais, durante um período de 4 dias. Para tanto, utilizaram dois sistemas, um massa/pasta com moldeira de estoque e outro com pasta em moldeira individual de acrílico, com até 2 viscosidades do material de moldagem. A espessura da pasta no interior do molde era de 0,5 mm no primeiro sistema e de 1,5 mm no segundo. As conclusões, segundo os autores foram que: "as siliconas de condensação apresentaram-se mais estáveis que os demais elastômeros avaliados; a precisão e a consistência, das siliconas de adição, foram melhores mantidos pelo uso de moldeiras individuais e adesivos para retenção; os polissulfetos, unidos a moldeiras individuais, apresentam um aumento progressivo no diâmetro do modelo com o passar do tempo, os modelos produzidos após 4 dias não foram mais nem menos efetivos do que as siliconas de condensação; o poliéter possui estabilidade intermediária entre o polissulfeto, a silicona de condensação ou a de adição, quando a técnica empregada envolve o emprego moldeira individual com uso do adesivo; o sistema massa/fluido para a silicona de adição, revelou uma perda de precisão, nos modelos obtidos por vazamentos múltiplos após 2 e 6 dias, e que parece não haver diferenças significantes entre as técnicas de simples e de dupla mistura, para os polissulfetos, quando se utiliza, para ambas, moldeira individual”. 
Em 1982, PAGNIANO et $\boldsymbol{a l}^{26}$, procurando saber mais sobre a estabilidade dimensional de resinas acrílicas utilizadas para confecção de moldeiras individuais, mensuraram as mudanças dimensionais lineares que ocorriam em 4 marcas de resinas acrílicas e as alteração apresentada pelos mesmos materiais quando imersos em água em ebulição por 5 minutos. As mensurações foram feitas durante um intervalo de 24 horas, contados após 15 minutos do inicio da espatulação, para determinar o período de maior estabilidade do material. Diante dos resultados, os autores do referido trabalho, concluíram que quanto maior o período de tempo aguardado para que uma moldeira de resina acrílica seja utilizada, mais estável esta será; idealmente dever-se-ia esperar por pelo menos 9 horas após o inicio da cura, os materiais testados se apresentaram comparativamente estáveis e se fosse necessário utilizar uma moldeira logo após esta ter sido fabricada, ela deveria ser colocada em água em ebulição por 5 minutos, e então resfriada antes do uso.

Em 1983, CLANCY, SCANDRETT \& ETTINGER ${ }^{13}$ estudaram a estabilidade dimensional de 3 elastômeros (o poliéter Polygel, a silicona de adição Reprosil e a silicona de condensação Elasticom), analisando os respectivos moldes tanto imediatamente como após 4, 24 e 48 horas, assim como também após 1, 2, 3 e 4 semanas. Os componentes dos materiais de moldagem foram misturados de acordo com as normas dos fabricantes e a massa resultante era pressionada (entre 1 e 5 minutos após o início da mistura) contra a superfície plana de um bloco cilíndrico de aço inoxidável, a qual apresentava vários sulcos. O elastômero ainda fluido era coberto por uma folha de polietileno, a qual por sua vez era coberta por uma placa de vidro; o conjunto era então imerso em água à temperatura de $32 \pm 2^{\circ} \mathrm{C}$, onde permanecia até se completar o tempo de polimerização indicado pelo respectivo fabricante. Os 75 moldes obtidos foram avaliados com auxílio de um microscópio comparador, cuja imagem era avaliada através de um sistema computadorizado. Afirmaram não ter havido diferença significante entre o comportamento do Reprosil e do Polygel, nos quais a variação dimensional foi pequena até a quarta semana. Relataram ainda que o Elasticom apresentou mudança dimensional significante já na idade de 4 horas. Notaram também que 
depois de 4 semanas o Reprosil ainda apresentava a melhor reprodução de detalhes, enquanto o Elasticom perdera muitos de seus detalhes já nas primeiras 24 horas.

Em 1984, VALDERHAUG \& FLØYSTRAND ${ }^{36}$ avaliaram a estabilidade dimensional de moldes obtidos com moldeiras de estoque metálicas e com moldeiras individuais de resina acrílica. Dois modelos-mestres foram confeccionados em metal, ambos possuíam dentes pilares (com superfície oclusal plana) na região de caninos e primeiro molares. Dois sulcos (em forma de cruz) com $5 \mu \mathrm{m}$ de largura foram gravados na superfície oclusal tornando possível a medição, com auxílio de um microscópio das distâncias entre os pilares tanto nos moldes como nos modelos. Os modelos foram fixados em aparelhos que fixavam a moldeira em uma única posição. Foram feitas moldagens com o Impregum e o Xantopren nas consistências média e leve, seguindo sempre as recomendações dos fabricantes. As medições foram realizadas imediatamente após a remoção dos moldes do modelo-mestre e após 1 e 24 horas. Todos os procedimentos foram realizados em ambiente com temperatura de $21^{\circ} \mathrm{C}$ e umidade relativa do ar $50 \%$. Afirmaram não haver diferença estatisticamente significante, entre as distâncias observadas nos moldes obtidos com os 2 diferentes tipos de elastômeros. Informando também que as pequenas diferenças dimensionais entre os poliéteres e as siliconas estão em oposição àquelas observadas por outros autores.

Em 1985, ARAÚJO \& JØRGENSEN ${ }^{3}$ para determinar a influência do volume e da espessura dos materiais de moldagem (Permlastic e President) no interior do molde, e também do tamanho da retenção cervical sobre a precisão dos troquéis de gesso obtidos, utilizaram um troquel de aço com forma troncocônica capaz de ajustar a altura da região cervical (correspondente ao sulco gengival) em 1, 2 ou 3 mm com a utilização de um de 3 anéis existentes. As diferentes espessura do material de moldagem (1, 2, 3 ou $4 \mathrm{~mm}$ ) foram determinadas pelos diferentes diâmetros internos das moldeiras perfuradas utilizadas para a realização da moldagem. gesso. Os materiais foram manipulados de acordo com as instruções dos fabricantes em ambiente com temperatura controlada em $22 \pm 2^{\circ}$ C. A polimerização dos materiais de 
moldagem ocorreu em recipiente com água a $37^{\circ} \mathrm{C}$, por 15 minutos. Os moldes foram vazados com gesso tipo IV Duroc após 10 minutos e aguardou-se 2 horas para a separação do troquel do molde, o qual era então imediatamente levado a um microscópio para que fossem registradas suas medidas e comparadas com às do troquel padrão. Os autores concluíram que ambos os fatores analisados afetaram a dimensão dos troquéis de gesso; os dados revelaram que o aumento da espessura do elastômero de 1 para 4 mm causou uma distorção maior do que o aumento da altura da região retentiva de 1 para 3 $\mathrm{mm}$.

Em 1988, SCHELB et al. ${ }^{30}$ avaliaram a compatibilidade de 14 gessos do tipo IV (dentre eles o Vel-Mix) com 3 poliéteres (Impregum, Permadyne e Polygel). Utilizara um placa de vidro de 4 polegadas quadradas sobre a qual foi feita uma linha de $20 \mu \mathrm{m}$ de acordo com a especificação ${ }^{\circ} 19$ da $\mathbf{A D A}^{1}$ para testes de compatibilidade de elastômeros com gessos. Esta placa foi moldada e os gessos vertidos sobre os moldes obtidos; assim, foram produzidas 4 amostras de cada uma das 42 combinações possíveis, gerando 168 espécimes, que depois da presa do gesso, eram avaliados por três pares de examinadores; quando o espécime apresentava uma linha visível em mais de 50\% de seu comprimento este era considerado como tendo "linha presente". Observaram que a linha foi reproduzida em todos os moldes; entretanto apenas 12,1\% foram identificadas nos modelos de gesso e das 42 combinações (elastômero/gesso), apenas 19 reproduziram a linha de $20 \mu \mathrm{m}$. Desta forma, os autores, concluíram que: a capacidade de reprodução de uma linha de $20 \mu \mathrm{m}$ de largura pode ser usada para determinar a compatibilidade entre os poliéteres e os gessos odontológicos; a combinação do Permadyne ${ }^{\circledR}$ com o Supercal ${ }^{\circledR}$ reproduziu a linha em $100 \%$ das vezes; os fabricantes deveriam identificar os gessos que são compatíveis com os materiais de impressão de sua fabricação.

Em 1994, MARCHESE ${ }^{22}$ avaliou a precisão de dois métodos de mensuração da fidelidade de troquéis de gesso: medição direta das dimensões dos toquéis (perfil), em 3 alturas do troquel, usando um microscópio comparador e um outro que avaliava o grau de desadaptação de uma coroa padrão ao troquel utilizando um microscópio de profundidade. Para isto, 
empregou o dispositivo de moldagem desenvolvido por ARAÚJO \& JØRGESEN $^{3}$, e testou 2 siliconas de adição (Provil-H e Basysilex) e uma mercaptana (Permlastic), em duas diferentes temperaturas de polimerização (23 $\pm 1^{\circ} \mathrm{C}$ e umidade $50 \pm 5 \%$, ou $37^{\circ} \mathrm{C}$ em água), com a técnica da duplamoldagem e para a confecção dos troqueis de gesso foi usado o Vel-Mix. O autor concluiu que: o método de medição direta dos diâmetros dos troquéis é inadequado para avaliar os mesmos; estatisticamente, o Baysilex e o Provil-H permitiram obter de troquéis significativamente mais fiéis do que o Permlastic; e que, estatisticamente, a temperatura de $37^{\circ} \mathrm{C}$ gerou piores resultados do que a de $23^{\circ} \mathrm{C}$.

Ainda em 1994, CHAI, TAN \& PANG $^{10}$ avaliaram o efeito do tempo sobre a dureza superficial e a estabilidade dimensional de materiais utilizados para se realizar registros intermaxilares (1 pasta zinco-enólica, 1 poliéter e 7 polivinilsiloxanos). Para a realização do teste de dureza superficial, todos os 9 materiais foram espatulados (segundo as indicações dos fabricantes) e as massas resultantes inseridas em uma matriz de "nylon" com 6,5 mm de espessura e 12,5 mm de diâmetro; obtendo-se, assim, 90 amostras (10 para cada um dos materiais testados), estas amostras foram levadas a um durômetro Shore-A e avaliadas com as idades de 30 minutos e 24 horas. O teste de estabilidade dimensional seguiu a Especificação $n^{0} 19$ da $\mathbf{A D A}^{1}$ para elastômeros, por este motivo, a pasta zinco-enólica não foi avaliada. Os autores concluíram que "houve diferença significante entre a dureza e a estabilidade dimensional dos materiais utilizados para o registro oclusal; que a estabilidade dimensional do poliéter foi significantemente menor do que a dos polivinilsiloxanos testados; que a porcentagem de alteração dimensional de todos os materiais estava dentro dos padrões estabelecidos pela Especificação $\mathrm{n}^{0} 19$ da ADA $^{1,}$.

Em 1995, TAN, CHAI \& WAYNE ${ }^{34}$ avaliaram o efeito do tempo de trabalho sobre a estabilidade dimensional e a capacidade de reprodução de detalhes de 7 elastômeros (1 poliéter, 1 polisulfeto e 5 polivinilsiloxanos). A espatulação dos materiais seguiu as normas da Especificação nº19 da $\mathbf{A D A}^{1}$, porém para poder se averiguar a influência do tempo de trabalho sobre os 
materiais, criou-se 10 grupos com diferentes tempos de trabalhos, entre os quais havia uma diferença de 30 segundos, sendo que o menor tempo de trabalho era de 30 segundos e o maior de 5 minutos. Para avaliação da estabilidade dimensional e da capacidade de reprodução de detalhes foi seguida a Especificação nº19 da $\mathbf{A D A}^{1}$. Os autores concluíram que "o tempo de trabalho definido pela reprodução de detalhes geralmente concorda com aquele determinado pela estabilidade dimensional, mas não com o indicado pelo fabricante”.

Em 1998, ANUSAVISE ${ }^{2}$ definiu que um material de moldagem “ideal” seria aquele “capaz de reproduzir com precisão a forma dos dentes e as suas relações com as estruturas vizinhas, devendo ainda ser suficiente elástico para ser removido das áreas retentivas e voltar à sua forma original sem sofrer distorções”. Comenta o fato de que os adesivo de moldeira não são intercambiável entre os diferentes materiais de moldagem e discorre sucintamente acerca de um método de avaliação da precisão dos materiais de moldagem que utiliza troquéis de aço padrão simulando dentes preparados, aos quais se adaptam perfeitamente as fundições padrões. A moldagem do troquelpadrão e o vazamento com gesso especial para troquel permitiriam uma avaliação do desajuste da fundição padrão ao troquel de gesso, sendo justificado ignorar-se qualquer alteração dimensional do gesso. Dentre as falhas mais comuns e suas causas nas moldagens com elastômeros, o autor cita que as distorções dos moldes poderiam ser causadas pela contração de polimerização e pela remoção prematura ou inadequada do molde da boca.

Também em 1998, VIANNA \& FREITAS $^{38}$ avaliaram o desempenho da silicona de condensação (Zetaplus / Oranwash), com o objetivo de verificar o grau de adaptação de uma coroa padrão aos respectivos troquéis de gesso tipo IV (Vel-Mix), usando um microscópio de profundidade. No processo de moldagem, promoveram diferentes graus de "alívio" no interior do molde do elastômero apresentado na forma de massa (Zetaplus), posteriormente completando com a pasta (Oranwash) utilizando o dispositivo de moldagem citado no trabalho de ARAÚJO \& JØRGESEN ${ }^{3}$. Através dos resultados, os autores, concluíram que as condições com a “alívio” de 1 e 2 mm conduziram a 
resultados semelhantes entre si, ambas melhores que a condição sem "alívio”. Chamaram atenção, além disso, para o fato de que seus troquéis sempre se apresentaram com dimensões maiores do que as do troquel padrão.

Ainda em 1998, CORSO et al. $^{14}$, apontando que os fatores primários causadores das alterações dimensionais do molde seriam “a contração térmica, a contração de polimerização e a perda de substâncias voláteis pelo material”, avaliaram os efeitos da mudança de temperatura sobre a estabilidade dimensional de moldes obtidos com o vinil-siloxano Express e o poliéter Impregum, por entenderem que havia carência de tais estudos. A partir de um troquel de aço, foram tomados cento e quarenta e quatro moldes, nos quais as moldeiras de resina acrílica comportavam o elastômero em uma espessura uniforme, de $3 \mathrm{~mm}$; metade destas moldeiras apresentavam furos, como forma de conferir retenção mecânica ao material de moldagem; a temperatura ambiental foi de $35 \pm 1^{\circ} \mathrm{C}$, tanto durante a moldagem como durante a primeira medição de cada troquel, a qual foi feita com um microscópio com acuidade de de $0,5 \mu \mathrm{m}$. Com um total de 144 espécimes, foram compostos 12 grupos, sendo 6 para cada elastômero. Metade das moldagens, para ambos materiais, foram executadas com moldeiras perfuradas e a outra metade com moldeiras não perfuradas. Cada combinação entre os dois materiais de impressão e os dois tipos de moldeiras foi armazenada por 24 horas em três diferentes temperaturas: 4, 23 e $40^{\circ} \mathrm{C}$; em seguida permaneciam por um tempo adicional de 2 horas à temperatura de $23^{\circ} \mathrm{C}$, quando era executada uma segunda leitura no tempo de 26 horas. Com base nos resultados observados, as seguintes conclusões foram extraídas: 1) a armazenagem de ambos os elastômeros à temperatura de $4{ }^{\circ} \mathrm{C}$ por 24 horas seguida de permanência em temperatura ambiente resultou em moldes ligeiramente expandidos que compensaram parcialmente a contração de polimerização do material; 2) armazenando o poliéter a $40{ }^{\circ} \mathrm{C}$ por 24 horas e então permanecendo em temperatura ambiente, também resultou em moldes ligeiramente expandidos; 3) os efeitos do uso de moldeiras perfuradas ou não, sobre a estabilidade dimensional de moldes obtidos de um troquel sem retenção, foram inconsistentes; 4) a média das alterações dimensionais registradas neste estudo variaram de 1 a $18 \mu \mathrm{m}$. 
Em 1998, PURK et al. ${ }^{28}$ avaliaram o efeito de diferentes temperaturas de armazenamento sobre a estabilidade dimensional de moldes de elastômeros (Impregum F e Mirror 3 Extrude). Para tanto, foram tomadas 40 impressões (5 para cada material e condição) de um troquel-padrão, confeccionado em aço inoxidável, que apresentava dois postes cilíndricos localizados na porção superior. Os moldes depois de obtidos, seguindo Especificação n ${ }^{\circ} 19$ da $\mathbf{A D A}^{1}$, eram submetidos a diferentes temperaturas $\left(-10^{\circ} \mathrm{C}, 24^{\circ} \mathrm{C}\right.$ e $\left.66^{\circ} \mathrm{C}\right)$ por um período de 8 horas, quando eram então mantidos a $24^{\circ} \mathrm{C}$ e preenchidos com gesso; para a confecção do grupo controle, os moldes eram mantidos por 2 horas a $24^{\circ} \mathrm{C}$ e em seguida preenchidos com gesso. A mensuração dos troquéis era feita através de um microscópio, por um único operador, com repetição de 10 vezes para cada uma de 6 diferentes medidas; quando, estas eram então comparadas com as originais do troquel-padrão. Dentre as conclusões dos autores, podemos destacar que “o Mirror 3 Extrude geralmente produz troquéis menores que o troquel-padrão na maioria dos parâmetros e condições. Enquanto o Impregum $\mathrm{F}$ geralmente produz troquéis maiores que o troquelpadrão em todas dimensões e condições de armazenamento”.

Em 1999, MARCHESE ${ }^{23}$ avaliou a fidelidade de troquéis de gesso, utilizando 2 técnicas de moldagem: dupla-moldagem (com espessura de 1 e 2 mm para a pasta do elastômero) e casquete (com $1 \mathrm{~mm}$ de espessura para o material). Foram utilizados 5 elastômeros (Express, Impregum F, Imprint, Permlastic e President); os moldes foram obtidos empregando o dispositivo de moldagem idealizado por ARAÚJO \& JØRGESEN ${ }^{3}$, e em seguida preenchidos com gesso tipo IV (Vel-Mix). As medições foram realizadas com um microscópio de medição de profundidade. Foram constatadas diferenças significativas entre as condições estudadas. O autor relatou ter concluído que: a técnica do casquete apresentou melhores resultados para os materiais Impregum F e Imprint, vindos a seguir o Express e o President (ambos com “alívio” de $2 \mathrm{~mm}$ ) e o Express (“alívio” de $1 \mathrm{~mm}$ ); o Permlastic e o Express, na técnica do casquete, apresentaram piores resultados que os anteriores, mas semelhantes entre si, sendo o President (casquete) semelhante a este último; o President (“alívio” de $1 \mathrm{~mm}$ ) foi o que apresentou pior resultado. 
Também em 1999, SAITO \& FREITAS ${ }^{29}$ avaliaram o desempenho de uma silicona de condensação (Optosil / Xantopren), com o objetivo de verificar o grau de adaptação de uma coroa padrão aos respectivos troquéis de gesso tipo IV (Vel-Mix), usando um microscópio de profundidade. No processo de moldagem, promoveram diferentes graus de "alívio" no interior do molde do elastômero apresentado na forma de massa (Optosil), posteriormente completando com a pasta (Xantopren) utilizando o dispositivo de moldagem citado no trabalho de ARAÚJO \& JØRGESEN ${ }^{3}$. Através dos resultados, os autores, relataram que as 2 condições com “alívio” (respectivamente de 1 e 2 $\mathrm{mm}$ ) também conduziram a resultados iguais entre si, ambas melhores que a condição sem “alívio", resultados semelhantes ao do trabalho homólogo de VIANNA \& FREITAS ${ }^{38}$.

Em 2000, SOARES \& MONDELLI ${ }^{32}$ avaliaram o reembasamento de moldes obtidos pela técnica de moldagem com resina acrílica gelada comparada a uma técnica convencional de moldagem com casquete preenchido com mercaptana. Para este fim, utilizaram o dispositivo desenvolvido por ARAÚJO \& JØRGESEN ${ }^{3}$ Os troquéis obtidos foram metalizados por eletrodeposição e analisados através de um microscópio de profundidade. Os autores concluíram que "a resina acrílica sem reembasamento apresentou maior alteração dimensional, os troquéis reproduzidos a partir de moldes de mercaptana apresentaram-se dimensionalmente mais próximos do padrão e o reembasamento proporcionou melhora significante na moldagem com resina acrílica gelada”.

Em 2001, MANTOVANI ${ }^{21}$ avaliou a fidelidade dimensional de troquéis de dois gessos tipo IV (Durone e Vel-Mix), obtidos a partir de moldes com 0,2mm de espessura, feitos com uma silicona de condensação (Oranwash). Para este fim, utilizou o dispositivo similar ao desenvolvido por ARAÚJO \& JØRGESEN $^{3}$. A autora concluiu que o gesso Vel-Mix possibilitou troquéis morfodimensionalmente mais fiéis nas condições estabelecidas, porém isso não significa que o Durone nas mesmas condições fosse inadequado.

Também em 2001, GOMES de SÁ, FREITAS \& MARCHESE $^{17}$ estudaram a fidelidade dimensional de toqueis de gesso tipo IV (Vel-Mix), 
confeccionados a partir de moldes obtidos com uma silicona de condensação (Oranwash), nos quais o casquete permitia uma espessura do material de moldagem de 0,2, 0,5 e 1,0 mm. Usaram para este estudo o mesmo dispositivo desenvolvido por ARAÚJO \& JØRGESEN ${ }^{3}$. Os autores concluíram que os troquéis estavam maiores que a estrutura original moldada, porém sem diferença estatisticamente significante entre eles.

Em 2002, SILVA ${ }^{31}$ avaliou a fidelidade morfo-dimensional de troquéis confeccionados através de três subseqüentes vazamentos de gesso tipo IV (VelMix) em um mesmo molde, este obtido de uma única silicona de condensação (Oranwash), utilizando a técnica do casquete, com o material de moldagem na espessura de 0,2 mm. Foi utilizado um dispositivo de moldagem semelhante ao idealizado por ARAÚJO \& JØRGESEN ${ }^{3}$ (e as medições foram realizadas com auxílio de um microscópio de profundidade. Concluiu-se que: 1) todos os troquéis apresentaram-se morfo-dimensionalmente maiores do que a estrutura original moldada; 2) ocorreu uma piora (aumento das dimensões) progressiva no segundo troquel, em relação ao primeiro, a qual aumentava ainda mais no terceiro.

Também em 2002, PIWOWARCZYK et al. $^{27}$ examinaram a precisão dimensional de elastômeros com apenas uma consistência (6 polivinilsiloxanos e 2 poliéteres), em 2 tempos de vida. Para tanto, mediram a distância entre pontos diretamente sobre as impressões, tais pontos estavam localizados na porção superior de postes cilíndricos que apresentavam a extremidade oposta imersa e retida mecanicamente no elastômero. O dispositivo utilizado consistia de uma base na qual ficavam inseridos os postes de modo que suas extremidades retentivas ficavam livres no interior de um anel que se ajustava à base; o elastômero era inserido no interior deste anel, e assim que estivesse polimerizado, a base era separada do anel expondo então o topo dos postes; antes da aplicação do material de impressão o dispositivo era temperado em água a $35 \pm 1{ }^{\circ} \mathrm{C}$. Os autores concluíram que os oito materiais investigados demonstraram precisão dimensional muito alta sob as condições experimentais utilizadas, com diferenças muito pequenas entre eles; e que não houve 
alterações significativas nas dimensões dos moldes entre os dois tempos de vida estudados.

Em 2003, GOMES de SÁ ${ }^{18}$ avaliou a fidelidade dimensional de troquéis de gesso tipo IV (Vel-Mix), obtidos a partir de moldes de um único elastômero (Impregum F), utilizando-se duas técnicas de moldagem, com casquete e dupla-moldagem, com ou sem contato cervical. O dispositivo de moldagem usado foi semelhante ao de ARAÚJO \& JØRGESEN ${ }^{3}$. O autor concluiu que: 1) o pior desempenho ocorreu com a moldeira perfurada, com desajuste médio de 397,70 micrometros; 2) o casquete com toque e aquecimento apresentou desempenho semelhante ao casquete sem toque e sem aquecimento e 3) o melhor desempenho ocorreu com o casquete sem toque e com aquecimento, com desajuste médio de 0,03 micrometros.

Em 2004, CHEN, LIANG \& $\mathbf{C H E N}^{11}$ avaliaram o efeito de diferentes tempos de estocagem e a proporção de carga inorgânica de vários materiais de impressão na precisão e estabilidade dos mesmos. Os materiais de moldagem estudados incluíram 3 alginatos (Algiace Z, CAVEX e Jeltrate), 5 siliconas comerciais (Aquasil, Exaflex - tipo regular, Express, Coltex fine e Rapid liner) e 2 siliconas experimentais desenvolvidas para este estudo (KE106A e KE106B). Foram realizadas impressões de 10 modelos metálicos que simulavam coroas preparadas, seguidas do vazamento do gesso, que ocorreu imediatamente para os alginatos e 30 minutos após para as siliconas; o segundo e o terceiro troquel de gesso foram feitos 1 e 24 horas depois, respectivamente. Os diâmetros da superfície oclusal dos troquéis de gesso e do metálico, foram determinados usando fotografias das superfícies feitas com uma câmera digital, as imagens foram medidas usando um sistema de integração digitalizado de fotomicrografia, para calcular alguma discrepância. Por esta razão, para cada impressão feita havia três marcas ao redor do modelo de gesso. Os autores concluíram que: 1) houve uma significante interação entre os materiais de moldagem e o tempo de estocagem na precisão da impressão; 2) dois tipos de siliconas de adição, Aquasil e Exaflex, tiveram maior precisão e estabilidade; 3) o material experimental KE106A teve menor precisão nos primeiro e segundo vazamentos e o alginato CAVEX teve a menor precisão no terceiro 
vazamento; 4) a estabilidade do CAVEX e Jeltrate foram às menos coerentes dos 10 materiais e diminuíram significantemente com o tempo de estocagem; 5) quando o material experimental teve uma baixa proporção de carga (KE106A), houve um significante aumento na discrepância dimensional quando comparado com o mesmo material com uma alta proporção de carga (KE106B). 
Proposição 


\section{3- Proposição}

No presente trabalho, o objetivo foi utilizar um elastômero (o poliéter Impregum Soft), com a técnica do casquete, e avaliar a fidelidade morfo-dimensional dos respectivos troquéis, sempre confeccionados com um gesso do tipo IV (o VelMix), ou vazado em cada um de três diferentes momentos, contados a partir da obtenção do respectivo molde (imediatamente, após 1 hora e após 2 horas), ou vazado através de três subseqüentes operações, agora num mesmo molde, também realizadas nos três momentos anteriormente citados. 
Material e método 


\section{4- Material e método}

\section{1 - Informações gerais}

Todas as figuras ilustrativas deste capítulo encontram-se reunidas num conjunto de folhas localizadas no seu final.

Todos os procedimentos práticos deste trabalho foram executados por um único operador, desde a moldagem até a avaliação dos respectivos troquéis de gesso, em um ambiente com controle de temperatura $\left(23 \pm 2^{\circ} \mathrm{C}\right)$ e de umidade relativa do ar $(50 \pm 10 \%)$.

Para a obtenção dos moldes, com a técnica do casquete, foi utilizado um poliéter, o Impregum Soft ${ }^{\circledR}$ (fabricado pela 3M/ESPE, dos EUA), na forma de pasta de viscosidade média, do lote número 171057, juntamente com o adesivo de moldeira específico, denominado Polyether Adhesive ${ }^{\circledR}$ (fabricado pela 3M/ESPE, da Alemanha), do lote número 151610.

Todos os troquéis aqui envolvidos foram confeccionados com um gesso tipo IV, o Vel-Mix $®$ (fabricado pela Kerr Corporation dos EUA), do lote número 3J0559.

Em todos os processos de pesagem aqui efetuados foi utilizada uma balança de precisão (modelo D7470, Sauter, de Edinburgh, Alemanha), regulada para pesagem de até 120 gramas, com acuidade de centésimo de grama.

As quantias de água foram mensuradas com o auxílio de uma pipeta comum, de vidro, com capacidade para 2 mililitros e acuidade de $0,1 \mathrm{ml}$.

Durante o vazamento das massas fluidas de gesso, foi utilizado um vibrador comum, de origem japonesa (G-C'S), sem esclarecimento do tipo de modelo.

O sistema que foi utilizado para avaliar o grau de adaptação dos troquéis aqui obtidos implica na necessidade do conhecimento das características do troquelpadrão que foi usado, bem como daquelas do dispositivo de moldagem no qual ele encontrava-se fixado, os quais são descritos a seguir.

\section{2 - Troquel-padrão e dispositivo de moldagem}

O troquel-padrão (apresentado no esquema da figura 1 com suas dimensões) era confeccionado em aço inoxidável, simulando um dente preparado para receber 
uma coroa total, inclusive apresentando uma região cervical retentiva, e ficava fixado no dispositivo de moldagem, na forma descrita a seguir.

No dispositivo em questão (cujo esquema é apresentado na figura 2) existiam duas plataformas, uma inferior (também denominada base) e outra superior (braço ou parte móvel). Em cada extremidade da base, encontrava-se fixada uma haste cilíndrica vertical, nas quais podia ser encaixado o braço, através de seus orifícios, de tal forma que este último podia ser deslocado em toda a extensão das citadas hastes. Na porção média do braço ficava fixado (através de um parafuso próprio) o troquelpadrão, o qual era suportado pelo cilindro auxiliar; dentre os três anéis espaçadores existentes, cuja função era delimitar a altura da região retentiva, foi aqui utilizado o de $3 \mathrm{~mm}$ de espessura. Neste dispositivo ainda existia um anel de manutenção de altura do braço, com seu parafuso próprio, assim como um sistema de fixação de moldeira cujos funcionamentos serão posteriormente descritos. O cilindro centralizador da moldeira, que aparece na figura 2, fazia parte do dispositivo original, porém não foi utilizado no presente trabalho.

Apesar de não constar no esquema do citado dispositivo, ainda deste fazia parte uma peça, denominada coroa-padrão, confeccionada também em aço inoxidável, a qual consistia de um anel, externamente com a forma cilíndrica, cujo furo central tinha a forma cônica. Ao ser adaptada adequadamente no troquel-padrão (como ilustrado pela figura 3), a coroa-padrão ficava com sua face superior situada no mesmo plano da "face oclusal” daquele. Na face oclusal do troquel-padrão, num ponto que foi escolhido ao acaso, próximo da borda, existia uma concavidade, a qual definia o que foi denominado como marca do ponto "Norte" (doravante denominado por $\mathrm{N}$ ), por analogia aos pontos cardeais.

Durante a citada adaptação, fazia-se com que esta marca ficasse alinhada radialmente com uma outra sua semelhante (encontrada numa posição excêntrica na face superior da coroa-padrão), apenas visando facilitar o futuro processo de avaliação dos troquéis. Esta aferição de altura podia ser efetuada no ponto N, assim como nos demais pontos Leste (L), Sul (S) e Oeste (O). A igualdade de alturas podia ser constatada através do dispositivo de medição mostrado na figura 4 (cujo funcionamento será posteriormente descrito), o qual consistia de um relógio micrométrico, acoplado a uma haste de sustentação, cuja base devia repousar sobre a 
mesma placa de vidro onde estivesse o troquel-padrão. O micrometro, cujo símbolo é $\mu \mathrm{m}$, foi a unidade de medição utilizada, a qual pertence ao conhecido Sistema Internacional de Unidades.

\section{3 - Confeç̧ão dos casquetes e sua fixação no dispositivo de moldagem}

Para confeccionar, em resina acrílica Duralay® (Reliance Dental, dos EUA), os casquetes de moldagem necessários, foram utilizados um troquel auxiliar e um casquete de níquel-crômio. O troquel auxiliar, confeccionado em gesso, havia sido obtido através da mesma técnica de moldagem que aqui será posteriormente detalhada; entretanto, sua região retentiva foi eliminada, pelo seu preenchimento com o mesmo material dele constituinte. O casquete de níquel-crômio, obtido através da técnica de fundição tradicionalmente usada em Odontologia, foi usinado até se mostrar adequadamente adaptado tanto ao troquel auxiliar, quanto ao troquel-padrão, e apresentar finalmente uma espessura uniforme de $0,2 \mathrm{~mm}$.

Assim, no casquete metálico (já encaixado no troquel-padrão) aplicava-se uma solução isolante, composta por uma cera de origem alemã (Hoechst V, tipo P 6456) dissolvida em benzina, a 10\% (peso/volume), aguardando-se 1 minuto para a evaporação do solvente. A seguir as cerdas de um pincel nº 00 (da série 206, fabricado pela Tigre, do Brasil) eram umedecidas com o líquido monomérico da RAAQ e em seguida eram feitas tocar no pó da referida resina; as pequenas porções da massa fluida (tradicionalmente denominadas de pérolas) assim obtidas eram gradativamente depositadas sobre o casquete metálico (que agora estava funcionando como espaçador), até cobri-lo completamente, exceto em uma pequena região da sua porção superior, assim ficando confeccionado um orifício cuja função era facilitar a remoção do casquete metálico do interior daquele de resina.

Esperava-se 30 minutos para que a resina sofresse polimerização e retiravase, do troquel auxiliar, o conjunto casquete de resina/espaçador. Com o auxílio de uma lâmina de bisturi, as rebarbas da borda inferior do casquete de resina eram removidas da borda do casquete metálico, a fim de possibilitar que este fosse daquele removido. 
Após tal remoção, o espaçador era recolocado no interior do casquete de resina, cujo orifício era então preenchido com a resina acrílica, aguardando-se mais 30 minutos para a respectiva polimerização. Com estes cuidados, então podia-se remover novamente o espaçador do interior da moldeira, agora utilizando uma cureta metálica comum. Um casquete concluído, em cujo interior ainda havia o espaçador, pode ser observado na figura 5 .

Foi necessário confeccionar uma placa de madeira, a qual servia para fixar cada uma das moldeiras no dispositivo de moldagem. Tal placa era colocada na base deste dispositivo e aí fixada pelo parafuso próprio; então, sobre ela era depositada uma pequena porção de godiva, que fora previamente aquecida até apresentar uma consistência plástica. Uma moldeira, contendo o casquete metálico, era então encaixada no troquel-padrão e, com a porção de godiva estando ainda em seu estado plástico, o braço do dispositivo era abaixado, até que a moldeira viesse a ficar presa à godiva, como é mostrado na figura 6 .

Após a godiva ter esfriado, o anel de manutenção de altura (identificado pela sigla AMA, na figura 2) era levantado (até tocar no braço do dispositivo), momento no qual era fixado por seu respectivo parafuso, de modo a guardar-se o registro desta posição. O braço era então removido da base, como se pode observar na figura 7 .

O casquete metálico era então novamente removido do interior da moldeira, como mostrado na figura 8, tendo servido também para centralizá-la, em relação ao troquel-padrão. Assim, cada operação de moldagem podia ter início.

\section{4 - Obtenção dos moldes}

Antes de cada moldagem, o troquel-padrão era limpo, através de uma gaze embebida em uma solução desengordurante composta de $50 \%$ de álcool etílico e 50\% de éter sulfúrico em volume/volume. Em seguida, através de um segundo pincel (semelhante ao anterior), era naquele aplicado a solução isolante já referida, cuja função agora era evitar adesão do elastômero ao metal do troquel.

A seguir, o adesivo para moldeira Polyether Adhesive ${ }^{\circledR}$, indicado pelo fabricante, era aplicado no interior do casquete, na sua borda e ainda na sua 
superfície externa, nesta numa extensão de 2,0 mm, operação esta cujo início é ilustrado pela figura 9. Era aguardada a secagem por 5 minutos, como determinado nas instruções do produto.

Sobre uma folha de papel impermeável (fornecida pelo fabricante do elastômero), colocado sobre a balança de precisão, foram pesados 1,4 g da pasta-base do poliéter e 0,2 g da respectiva pasta-catalizadora, assim obedecendo-se à proporção de 7:1 (em peso), recomendada pelo fabricante.

Sobre a mesma folha, efetuava-se a mistura das pastas, por 30 segundos, usando-se uma espátula metálica $\mathrm{n}^{\circ} 24$. A pasta homogênea resultante era colocada, com o auxílio da própria espátula referida, no casquete, preenchendo-o com grande excesso, na forma ilustrada pela figura 10; para efetuar este preenchimento, despendiam-se cerca de 10 segundos. Então, o braço do dispositivo era encaixado nas hastes da base, abaixado (20 segundos mais tarde), para assim efetuar-se a moldagem propriamente dita, e fixado através do seu parafuso próprio. Naquela ocasião, o material de moldagem, por ser extremamente fluido, escoava na forma ilustrada pela figura 11. Após mais 45 segundos, invertia-se a posição do dispositivo de moldagem, assim sendo ele mantido, com as mãos, por cerca 15 segundos, quando então o poliéter escorria, assim formando uma espécie de colarinho ao redor da base do troquel-padrão, como pode ser observado na figura 12. A função desse colarinho era possibilitar a criação de uma pequena base circular no futuro troquel de gesso. Restabelecia-se então a posição original do dispositivo, aguardando-se que a polimerização ocorresse por 10 minutos, contados a partir do início da referida mistura dos componentes.

Decorrido tal tempo, o braço do dispositivo de moldagem era novamente retirado de sua base, assim efetuando-se a desmoldagem. Com o auxílio de uma espátula tipo Le Cron, o casquete era então destacado da placa de madeira, ocasião na qual o molde era analisado a olho nu, por um tempo padronizado de 15 segundos, para detecção de eventuais imperfeições (tais como bolhas de ar, fendas ou dobras), as quais promoveriam seu descarte e consequentemente a repetição de todo este processo. Se fosse considerado adequado, o molde estava pronto para que fosse confeccionado o respectivo modelo; porém sendo esperados 5 minutos (contados a 
partir do momento da desmoldagem), para se permitir a eventual libertação de tensões.

\section{5 - Confecção dos troquéis.}

Para confeccionar cada troquel, utilizava-se $5 \mathrm{~g}$ de gesso e $1 \mathrm{ml}$ de água deionizada, misturados com uma espátula metálica número 24, numa tigela elástica comum (com capacidade para $50 \mathrm{ml}$ ), mantida sobre o vibrador em funcionamento, durante todo o tempo de mistura, que foi de 1 minuto. Com a mesma espátula usada durante a fase de mistura dos componentes, a massa fluida assim resultante era imediatamente vertida no molde, em pequenas porções, até se preencher o já referido colarinho, em toda sua altura. Decorridos 40 minutos, contados do início da espaulação, o troquel era removido do molde, ocasião na qual recebia um número de identificação.

Foi confeccionado um montante de cincoenta troquéis, divididos em cinco grupos com dez elementos em cada um. Cada grupo era caracterizado pelo fato do molde ter sido usado ou para se construir apenas um troquel ou para consecutivamente três troquéis, combinadamente com o momento no qual o gesso havia sido vertido no molde, como é explicado a seguir.

Num primeiro molde, o gesso era consecutivamente vertido por três vezes, para assim serem consecutivamente confeccionados três troquéis. Apesar de ter existido o tempo de relaxamento já citado, o primeiro destes troquéis era considerado como proveniente de um vazamento efetuado imediatamente após o respectivo molde ter sido considerado adequado, razão pela qual este tipo de troquel era considerado como pertencente ao grupo nomeado com a sigla R0, na qual a letra inicial aponta a ocorrência de repetidos vazamento no mesmo molde, seguida do número representativo de quanto tempo de demora existiu até o vazamento ser efetuado, o qual neste caso foi zero; este troquel era removido do molde 40 minutos após o início da mistura do gesso com a água. O segundo destes troquéis era proveniente de um vazamento também efetuado naquele primeiro molde, porém quando o molde tivesse alcançado a idade de uma hora, obviamente após o primeiro modelo já ter sido dali removido; razão pela qual este tipo de troquel era considerado 
como pertencente ao grupo nomeado com a sigla R1, na qual o número indica a idade do molde (em horas), quando o vazamento foi efetuado. O terceiro destes troquéis era proveniente de mais um outro vazamento também efetuado naquele primeiro molde, porém quando o molde tivesse alcançado a idade de duas horas; razão pela qual este tipo de troquel era considerado como pertencente ao grupo nomeado com a sigla $\mathbf{R 2}$, na qual a idade do molde era de duas horas, no momento do vazamento.

Num segundo molde, o gesso seria teoricamente vertido uma única vez, para nele ser imediatamente confeccionado um único troquel. Ora, esta situação (a qual poderia ser denominada de U0, com a letra indicando um único vazamento num mesmo molde) seria equivalente à já citada situação R0 e, por esta razão, aquele grupo não foi confeccionado.

Assim, naquele segundo molde, o gesso era vertido uma única vez, para nele ser confeccionado um único troquel, entretanto com o respectivo vazamento do gesso efetuado apenas quando o molde tivesse alcançado a idade de uma hora, de forma análoga à anteriormente explicada. Este tipo de troquel era considerado como pertencente ao grupo nomeado com a sigla $\mathbf{U 1}$.

Num terceiro molde, o gesso também era vertido uma única vez, igualmente para nele ser confeccionado um único troquel, entretanto com o respectivo vazamento do gesso efetuado apenas quando o molde tivesse alcançado a idade de duas horas. Este tipo de troquel era considerado como pertencente ao grupo nomeado com a sigla $\mathbf{U} 2$.

\section{6 - Medição da fidelidade dos troquéis.}

Cada troquel considerado adequado foi avaliado, vinte e quatro horas após a respectiva desmoldagem, quanto ao seu grau de fidelidade morfo-dimensional, através da verificação do desajuste da coroa-padrão nele adaptada, tarefa efetuada com o dispositivo de medição.

Para tanto, era necessário que cada troquel viesse a ficar com o plano de sua face oclusal posicionado perpendicularmente ao longo eixo da ponta do relógio micrométrico do sistema de medição, tarefa esta denominada nivelamento. Este 
posicionamento era conseguido com o auxílio de um aparelho denominado verticulador (fabricado pela Bio-art, de São Carlos-SP), que sofreu uma adaptação com intuito de capacitá-lo para a função requerida. Tal adaptação consistiu em fixarse uma caixa de madeira (contendo uma pequena porção de massa de modelagem) em sua base e um cilindro oco (centralizador) em seu braço.

Assim, estando o braço do verticulador colocado sobre a bancada de trabalho, um troquel era então cuidadosamente introduzido no orifício do cilindro centralizador, até que porção superior da base daquele tocasse em toda a extensão da borda deste último. Então, o ramo inferior do verticulador era acoplado ao braço e abaixado, até que a base do troquel viesse a ficar presa na massa de modelar; nesta ocasião, esta era comprimida contra a base do troquel, de modo que este viesse a ficar mais firmemente preso naquela posição. A base do verticulador era então removida do braço e colocada sobre a bancada de trabalho, agora com sua face superior voltada para cima, quando então o troquel era considerado como adequadamente nivelado.

A coroa-padrão era então acoplada ao troquel de gesso e adaptada por delicados golpes aplicados digitalmente. Então o referido conjunto, com a coroapadrão posicionada no troquel, era levado ao dispositivo de medição, o qual já se encontrava sobre a placa de vidro.

O troquel era colocado sob a ponta ativa do micrômetro (com capacidade de leitura até 1000 micrometros e acuidade de 1 micrometro), o qual era abaixado, até que sua ponta tocasse suavemente o gesso. O relógio micrométrico era novamente abaixado, desta vez até que o ponteiro acusasse uma descida de 200 micrometros, quando era então firmemente imobilizado. Esse ajuste permitia que a faixa de trabalho do relógio micrométrico fosse adequada.

Uma tira de poliéster (com espessura de 50 micrometros) era colocada embaixo da ponta ativa do micrômetro, com o intuito de evitar que a força exercida pela ponta (de cerca de 1 Newton) causasse dano à superfície do troquel ou à da coroa-padrão. Na figura 13 é ilustrada essa situação.

Antes que fosse iniciada a medição propriamente dita, a ponta ativa do micrômetro era levantada, com o auxílio de uma pinça, permitindo assim o 
deslocamento do troquel, de tal forma que a referida ponta, após ser abaixada, ficasse indiretamente apoiada num ponto da borda da coroa-padrão, ainda protegida pela fita de poliéster. Nesta situação, era verificado se, numa corrida circular, todos os pontos da borda da citada coroa encontravam-se, tanto quanto possível, na mesma altura; esta tarefa era realizada pela movimentação do troquel e a condição era consierada adequada, apenas se fossem detectados desníveis inferiores a 100 micrometros; caso contrário, todo o processo de nivelamento era refeito.

Para efetuar a medição propriamente dita, fazia-se inicialmente com que a ponta ativa do micrômetro viesse a incidir sobre a borda superior da coroa-padrão, na posição N, registrando-se então o valor numérico acusado pelo respectivo ponteiro; em seguida, era feito com que a referida ponta ativa viesse a incidir sobre o gesso, o mais proximamente possível do ponto de leitura anteriormente referido, momento no qual este segundo número era anotado; a diferença entre estes dois valores numéricos era considerado o valor do desnível, naquela região. Este mesmo procedimento era também executado para as regiões L, S e O, este ciclo era repetido por mais duas vezes, sendo assim obtidos 12 valores de desnível, cuja média aritmética passava a ser considerada como sendo o valor do desnível encontrado para aquele troquel, o que indiretamente indicava seu grau de fidelidade. Caso a coroa-padrão se apresentasse mais baixa que o troquel, o valor do desnível era acrescido do sinal indicativo de numeral negativo, ocorrendo o inverso para o caso oposto.

Os valores de fidelidade verificados nos troquéis foram submetidos à análise estatística apropriada. 


\section{Ilustrações do texto do capítulo de Materiais e métodos.}

As legendas das ilustrações aqui encontradas estão escritas de modo resumido, visto que explicações mais detalhadas são encontradas no respectivo texto.

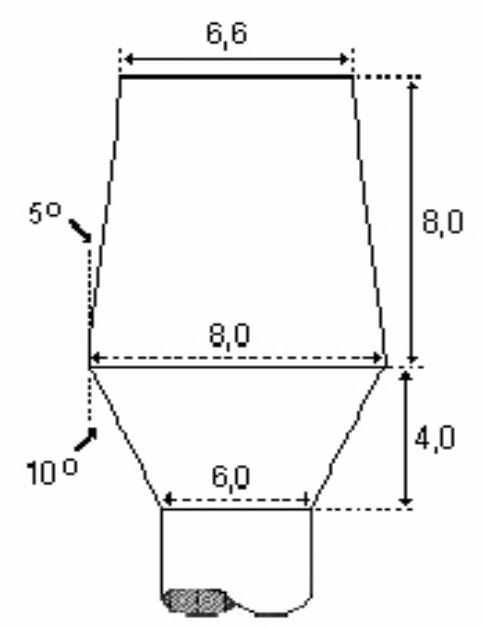

Figura 1. Esquema (modificado do original de Marchese $^{22}$ ) do troquel-padrão, com suas distâncias expressas em milímetros e seus ângulos em graus.

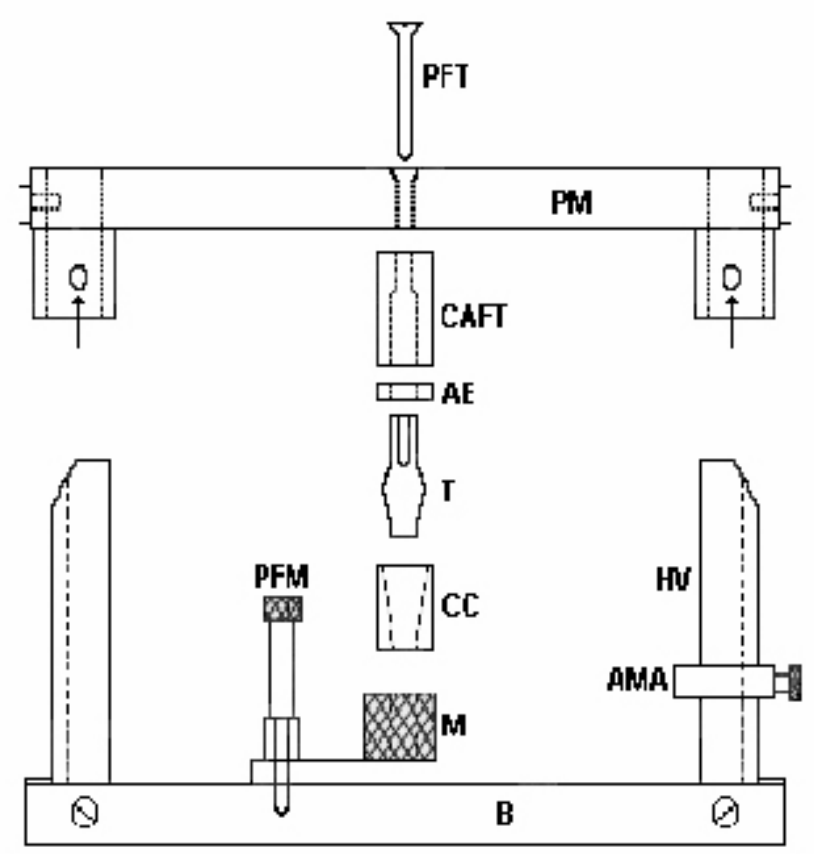

Figura 2. Esquema (modificado do original de Marchese $^{22}$ ) do dispositivo de moldagem utilizado. As letras e siglas identificam as partes descritas no texto: B - base; PM - parte móvel ou braço; HV - haste vertical; M - moldeira; PFM - parafuso fixador da moldeira; $T$ - troquelpadrão ; PFT - parafuso fixador do troquel-padrão; CAFT - cilindro auxiliar de fixação do troquel-padrão; AMA - anel de manutenção de altura da parte móvel; AE - anel espaçador e CC - cilindro centralizador. 


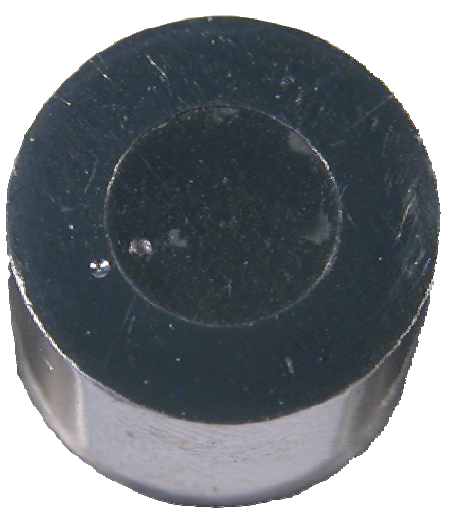

Figura 3. Troquel-padrão com a coroa-padrão.

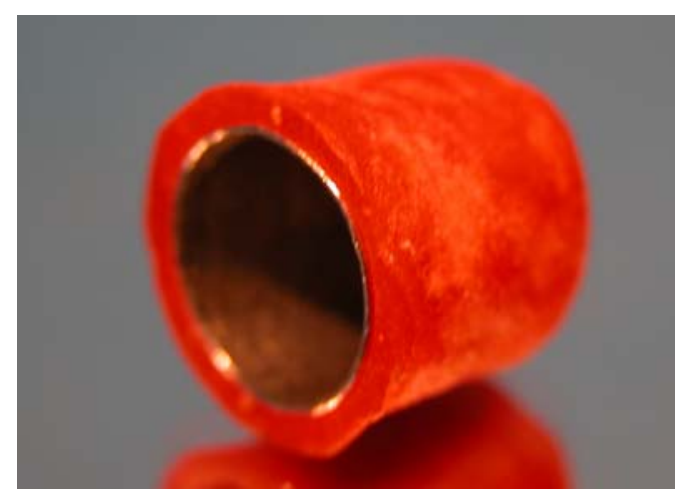

Figura 5. Casquete de resina, com espaçador ainda dentro.

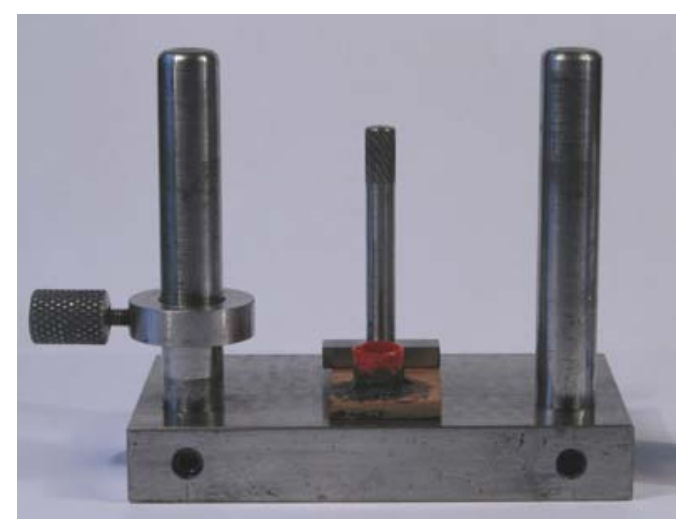

Figura 7. Casquete em posição sem o braço do dispositivo de moldagem.

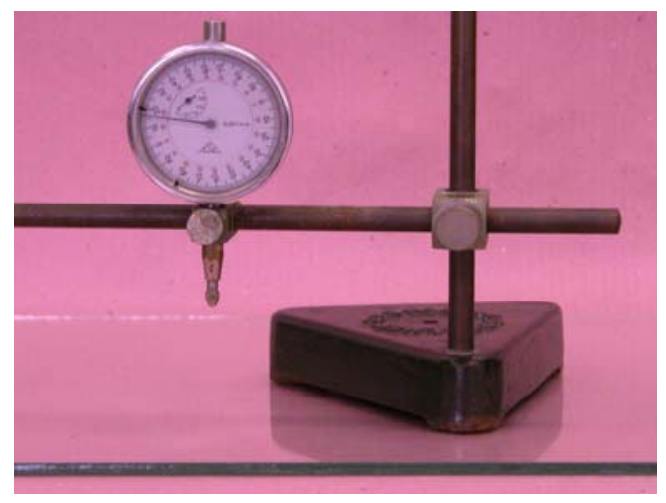

Figura 4. Foto do dispositivo de medição.

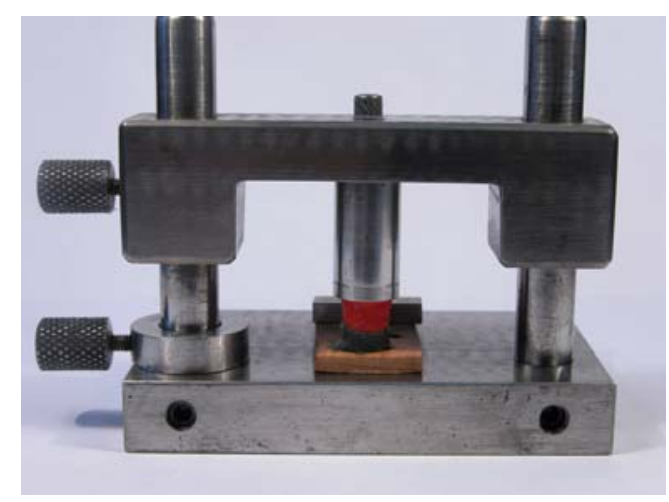

Figura 6. Casquete em posição no dispositivo de moldagem.

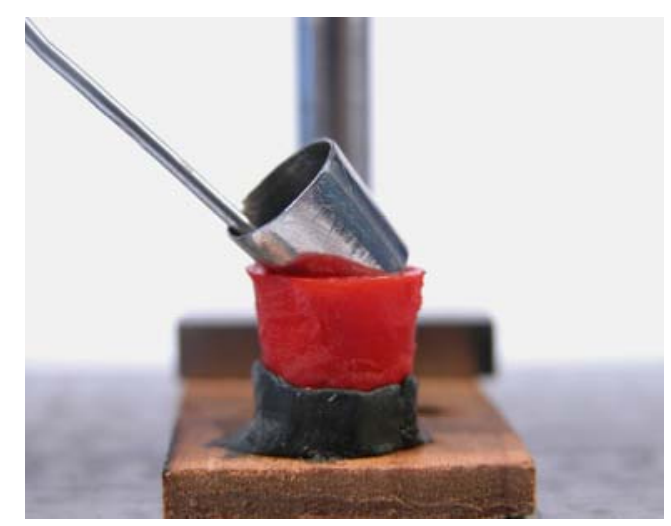

Figura 8. Momento da remoção do espaçador de dentro de um casquete. 


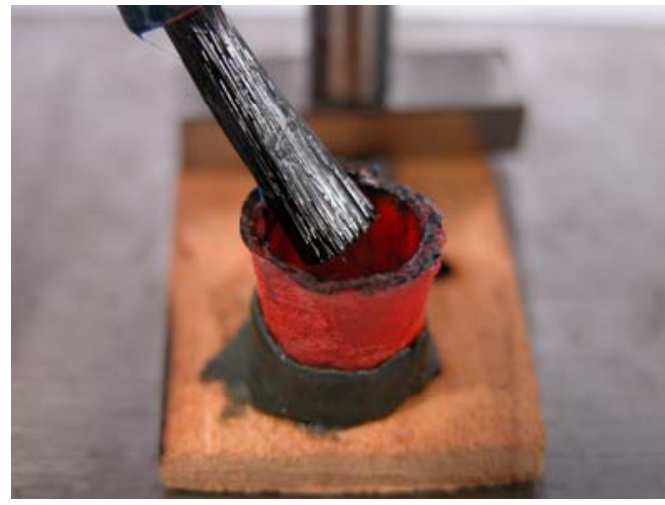

Figura 9. Adesivo sendo aplicado num casquete.

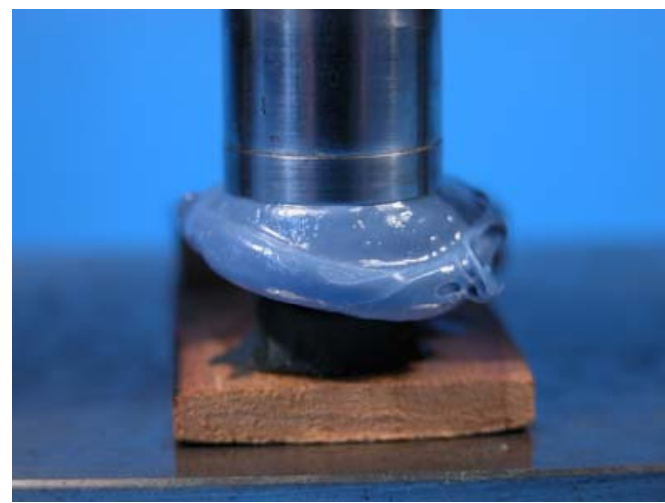

Figura 11. Escoamento do elastômero durante a moldagem.

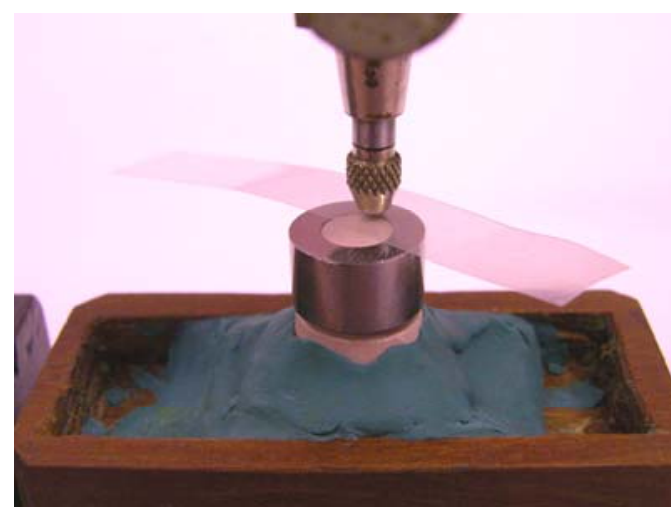

Figura 13. Tira de poliéster colocada embaixo da ponta ativa do micrômetro.

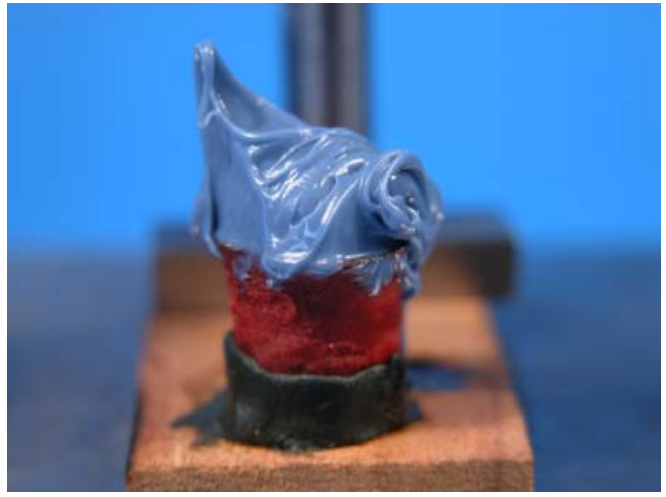

Figura 10. Casquete, preenchido com grande excesso de elastômero.

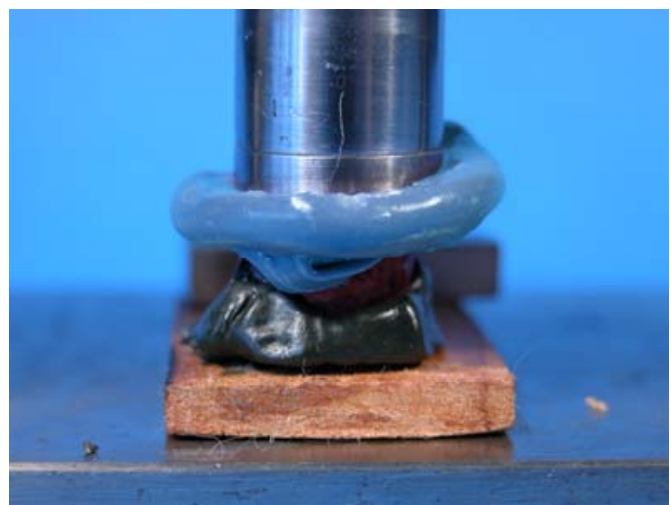

Figura 12. Formação do colarinho ao redor da base do troquel-padrão. 
Resultados 


\section{5- Resultados}

Na tabela 1 podem ser encontrados os resultados dos desajustes verificados (expressos em micrometros) nos troquéis das 5 condições estudadas. Tais valores expressam a diferença de altura entre a borda oclusal da coroa-padrão e a face oclusal de cada troquel de gesso; eles foram sempre positivos, pois todas as coroas ficaram mais altas que a face oclusal do troquel em questão, não se adaptando completamente a ele.

Tabela 1 - Valores individuais (em micrometros) da adaptação da coroa-padrão em cada troquel de gesso, para cada uma das cinco condições já descritas, com sua média (m), seu desvio-padrão (dp) e seu coeficiente de variação (cv).

\begin{tabular}{c|r|r|r|r|c|}
\hline Espécime & R0/U0 & R1 & R2 & U1 & U2 \\
\hline $\mathbf{1}$ & 67,1 & 133,4 & 193,4 & 97,1 & 239,8 \\
\hline $\mathbf{2}$ & 141,8 & 316,8 & 342,8 & 66,7 & 429,6 \\
\hline $\mathbf{3}$ & 105,9 & 115,9 & 169,7 & 119,5 & 381,5 \\
\hline $\mathbf{4}$ & 41,6 & 58,5 & 68,3 & 110,2 & 219,8 \\
\hline $\mathbf{5}$ & 88,1 & 88,8 & 129,3 & 77,1 & 328,1 \\
\hline $\mathbf{6}$ & 87,7 & 111,5 & 125,9 & 107,1 & 276,4 \\
\hline $\mathbf{7}$ & 44,9 & 141,3 & 214,7 & 147,7 & 331,8 \\
\hline $\mathbf{8}$ & 113,2 & 336,3 & 343,5 & 165,1 & 519,8 \\
\hline $\mathbf{9}$ & 55,3 & 134,4 & 142,0 & 125,2 & 203,1 \\
\hline $\mathbf{1 0}$ & 61,9 & 102,9 & 115,8 & 126,8 & 303,7 \\
\hline \hline $\mathbf{m}$ & $\mathbf{8 0 , 7 5}$ & $\mathbf{1 5 3 , 9 8}$ & $\mathbf{1 8 4 , 5 4}$ & $\mathbf{1 1 4 , 2 5}$ & $\mathbf{3 2 3 , 3 6}$ \\
\hline $\mathbf{d p}$ & $\mathbf{3 2 , 5 3}$ & $\mathbf{9 4 , 2 5}$ & $\mathbf{9 3 , 1 3}$ & $\mathbf{2 9 , 8 4}$ & $\mathbf{9 8 , 9 4}$ \\
\hline $\mathbf{c v}$ & $\mathbf{0 , 4 0}$ & $\mathbf{0 , 6 1}$ & $\mathbf{0 , 5 0}$ & $\mathbf{0 , 2 6}$ & $\mathbf{0 , 3 1}$ \\
\hline
\end{tabular}

Com os dados desta tabela, montou-se o gráfico 1, procurando-se facilitar o entendimento global dos resultados obtidos.

Os referidos valores sofreram uma transformação logarítmica (assim tendo sido aprovados quanto ao critério de homogeneidade de variâncias), para então serem submetidos à analise de variância, a 1 critério de classificação, modelo fixo, tendo sido encontrado um $\mathrm{F}_{\mathrm{obs}}=16,02$, mostrando que existiam diferenças significantes entre as condições estudadas, a um nível de significância de 0,01. 


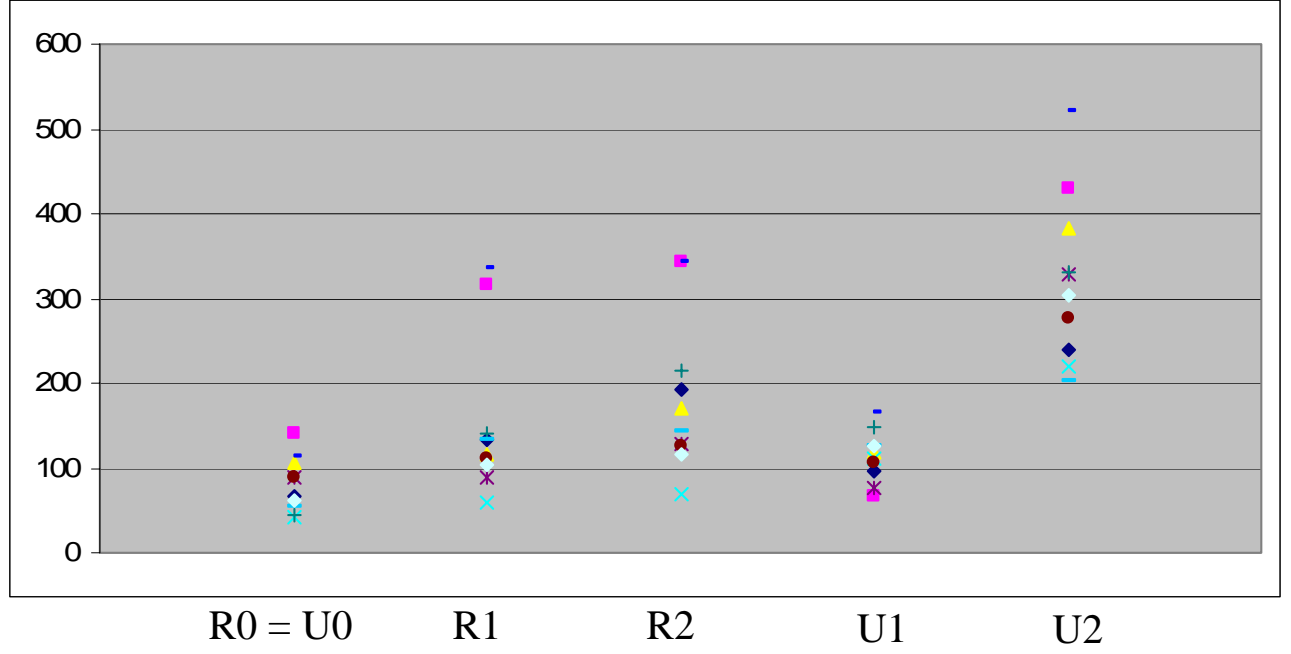

Gráfico 1 - Ilustrativo da tabela 1, com valores expressos em micrometros.

Consequentemente, foi necessária a aplicação de um teste de comparações múltiplas, tendo sido escolhido o de Tukey, ao nível de significância de 5\%, que demonstrou não existir diferença significante entre os grupos R0/U0 e U1, nem entre os grupos U1, R1 e R2, sendo o todos os anteriores diferentes do grupo $\mathbf{U} 2$. 
Discussão 


\section{6- Discussão}

No presente capítulos, inicialmente são tecidas considerações a respeito do material e do método aqui utilizado; ao final, são comentados os resultados obtidos, comparados aos de outros pesquisadores, quando isto for possível.

\section{1 - Acerca dos materiais e método aqui utilizados}

O controle ambiental da temperatura e da umidade relativa foi feito tentando-se obedecer às normas da $\mathbf{A D A} \mathbf{A}^{1}$, que estabelecem $23 \pm 1^{\circ} \mathrm{C}$ e $50 \pm 5 \%$. Entretanto, com os equipamentos existentes no laboratório onde os presentes ensaios foram realizados, foi possível apenas se obter uma variação de $23 \pm 2{ }^{\circ} \mathrm{C}$ e de $50 \pm 10 \%$.

Decidiu-se usar apenas a técnica do casquete, visto que esta sempre havia conduzido a resultados melhores que a de dupla moldagem, como pode ser comprovado nos trabalhos de GOMES DE SÁ ${ }^{18}$ e de MARCHESE ${ }^{23}$.

A decisão de se analisar um poliéter, qualquer que fosse sua marca, foi devido ao fato que esses materiais sofrem polimerização por adição, o que, em teoria, ajudaria a se obter moldes mais fiéis, uma vez que não seriam gerados produtos voláteis, entre outros aspectos.

A decisão de se estudar especificamente o poliéter Impregum Soft foi tomada com base em vários aspectos. Um primeiro deles está relacionado a uma mudança de nomes (e consequentemente eventuais mudanças em sua fórmula, as quais nunca foram claramente estabelecidas), pois este produto, antigamente denominado apenas como Impregum, posteriormente teve seu nome alterado para Impregum F; a mesma dúvida surge em relação aos produtos denominados Impregum Penta Soft e Impregum Penta, referidos no trabalho de PIWOWARCZYK et al. ${ }^{27}$. Aliás, em 1979, EAMES et al. ${ }^{16}$ Informaram ter utilizado um produto denominado Impregum, fabricado por Premier Dental Products Co., de Norristown, na Pensilvania; ora, não existe nenhuma menção é feita à ESPE, empresa fabricante dos demais produtos que utilizam este nome-fantasia. Complicando ainda mais este quadro, em 1994, no trabalho de CHAI, TAN e PANG ${ }^{10}$ é mencionado o uso de um poliéter, o Ramitec, fabricado por ESPE/Premier, 
curiosamente uma firma de Norristown, na Pensilvania. Será que este último não era o nome então dado, naquele pais, ao produto que aqui conhecíamos como Impregum, ou talvez como Impregum F? Um segundo aspecto é que o Impregum (falando-se genericamente e assim entendendo-se o produto fabricado pela firma alemã ESPE, hoje associada à 3M, pelo menos aqui no Brasil) tem sido utilizado em trabalhos de outros pesquisadores como PURK et al. ${ }^{28}$, VALDERHAUG \& FLØYSTRAND $^{36}$, VALLE $^{37}$ e TAN CHAI \& WAYNE ${ }^{34}$, entre outros trabalhos aqui compulsados, apesar dele não ter sido sempre utilizado com a técnica do casquete.

Segundo a Norma da $\mathbf{A D A}^{1}$, os materiais de moldagem elastoméricos podem ser apresentados em quatro viscosidades: muito alta, alta, média ou baixa. Para este trabalho, foi escolhido se trabalhar com um uma pasta de viscosidade média (termo com o mesmo significado de fluidez média), por acreditar-se que esta consistência seja a mais utilizada pelos dentistas em geral, entretanto, uma pasta de viscosidade alta teoricamente teria menor contração de polimerização, uma vez que esta apresenta maior quantidade de carga.

A escolha do adesivo de moldeira seguiu o conceito básico de que nenhum deles é intercambiável entre os diferentes materiais de moldagem, como salientado inclusive por ANUSAVISE ${ }^{2}$.

Para a confecção dos troquéis, o gesso Vel-Mix (classificado como do tipo IV ou especial) foi escolhido por ter boas resistências mecânicas, uma expansão normal de presa muito pequena, como relatado por ANUSAVISE ${ }^{2}$, e já ter sido avaliado quanto a sua precisão por SCHELB et al. ${ }^{30}$ e MANTOVANI ${ }^{21}$, além disso tal gesso tem sido o mais utilizado, para esta função, na maioria dos trabalhos científicos acerca do tema, COmo os de MARCINAK et al. ${ }^{24}$, STACKHOUSE Jr. $^{33}$, EAMES et al. ${ }^{15}$ e EAMES et al. ${ }^{16}$, entre outros.

Para confeccionar os casquetes de moldagem, a Duralay foi escolhida, por ser a resina acrílica mais utilizada também na maioria dos trabalhos científicos acerca do tema, como os de MANTOVANI ${ }^{21}$, MARCHESE ${ }^{23}$, SOARES \& MONDELLI ${ }^{32}$, SAITO \& FREITAS $^{29}$ e VIANNA \& FREITAS $^{38}$, entre outros. 
O casquete espaçador foi originalmente confeccionado em uma liga de níquelcrômio, com o intuito de que ele tivesse grande resistência à deformações plásticas, exatamente por ter uma espessura muito pequena $(0,2 \mathrm{~mm})$. Foi surpreendente detectar que este casquete sofreu deformações plásticas, visíveis de maneira nítida, ao contrário do que era esperado, quando ele era removido do casquete de resina acrílica. Entretanto, sua forma original podia ser facilmente restabelecida.

Na literatura pertinente, são encontrados dois tipos de processos usados para se analisar a acuidade dos materiais de moldagem, independentemente de qual técnica tenha sido usada. O primeiro destes tipos é denominado direto, pois as mensurações são feitas diretamente no molde obtido como no trabalho publicado por CLANCY, SCANDRETT \& ETTINGER ${ }^{13}$. No segundo, denominado indireto, tais mensurações são efetuadas no troquel que foi obtido pelo vazamento de gesso no respectivo molde.

Neste trabalho, as medições foram realizadas sobre troquéis de gesso, e não diretamente nos moldes, por se acreditar que este método é o que apresenta resultados que realmente expressam a realidade. Especificamente, a avaliação da fidelidade do troquel através da adaptação da coroa-padrão a ele, e não através da medição direta de suas dimensões, parece ser o método mais adequado. Isto ficou claramente comprovado no trabalho de MARCHESE ${ }^{22}$, após ele ter medido os diâmetros (em varias alturas diferentes) de vários troquéis de gesso, usando um microscópio comparador, e ter encontrado valores menores que os do troquel-padrão; ora, a expectativa de que a coroapadrão ficasse mais baixa, quando fosse adaptada a estes troquéis; não se confirmou, tendo ela ficado mais alta, em muitas destas situações. A única conclusão que aparentemente pode ser tomada é que o método de medição dos diâmetros (denominado pelo referido autor como método do perfil) não conduzia a resultados confiáveis.

Quando se usa o método de análise através da coroa-padrão, o fato dela se apresentar mais alta ou mais baixa do que o troquel de gesso não indica que este está respectivamente apenas maior ou menor do que o troquel-padrão. Deve ser lembrado que, durante sua polimerização, o elastômero não apenas se contrai em direção às paredes do casquete (como futuramente ainda será discutido em detalhes), assim aumentando as dimensões da cavidade virtual existente em seu interior. 
Concomitantemente com esta contração, ao conjunto já estão sendo incorporadas distorções, visto que na realidade a espessura do elastômero é maior que 0,2 mm, em relação ao casquete, nas regiões angulares oclusal e cervical do troquel-padrão. Este problema de distorções se tornará ainda mais grave, por ocasião da expansão normal de presa do gesso, pois mesmo aceitando-se que o gesso escolhido seja um material razoavelmente bastante homogêneo (apesar de na realidade não ser absolutamente isotrópico), visto que as dimensões da sua massa, dentro do molde, não são iguais em todas as direções. Então, às alterações dimensionais homogêneas sofridas pelo elastômero e pelo gesso, as quais são respectivamente uma contração e uma expansão, no final são incorporadas ao troquel, acompanhadas das distorções, que são alterações dimensionais heterogêneas.

Como este problema é complexo e consequentemente é de difícil explicação, cabe aqui sua exposição através do seguinte exemplo. Quando a coroa-padrão é adaptada a um troquel de gesso e se apresenta mais alta do que este, isto não indica obrigatoriamente que o troquel esteja maior do que o troquel-padrão, em todas as dimensões. Ela pode ser indicativa, por exemplo, apenas de que alguma distância, mesmo que seja apenas em alguma altura do diâmetro do troquel de gesso, está maior do que a mesma dimensão do troquel-padrão. Em outras palavras, o fato da coroa-padrão ficar mais alta do que o troquel de gesso pode indicar tanto que este esteja maior que o troquel-padrão, apenas em uma altura ou em todas elas.

Apesar de poder ser reconhecido que o método da coroa-padrão não é o ideal, pois ele não consegue mostrar separadamente o que é distorção e o que é alteração dimensional homogênea (contração ou expansão), mas sim englobando estes fenômenos, ele parece entretanto ser o melhor, dentre os demais métodos atualmente conhecidos.

$\mathrm{O}$ dispositivo de moldagem aqui utilizado era semelhante àquele original utilizado primeiramente por ARAÚJO \& JÖRGENSEN ${ }^{3}$ e posteriormente por GOMES de SÁ $^{18}$, MANTOVANI ${ }^{21}$, MARCHESE ${ }^{22}$, SAITO \& FREITAS $^{29}$ e VIANNA \& FREITAS $^{38}$, entre outros. Entretanto, ele apresentava basicamente 2 modificações em relação ao original. A primeira era em relação à coroa-padrão, que agora apresenta uma precisão de encaixe ao troquel-padrão bem mais sofisticada, uma 
vez que em quaisquer um dos 4 pontos de medição não existe diferença de altura entre ela e o troquel-padrão, mesmo quando eles não estejam radialmente alinhados entre si. Uma segunda modificação foi a utilização de mais uma haste de sustentação, o que confere ao aparelho uma maior estabilidade, sem oscilação de seu braço durante o abaixamento para execução da moldagem propriamente dita.

Os resultados do presente trabalho não podem ser comparados com aqueles obtidos por outros autores (como por exemplo CORSO et al. ${ }^{14}$, CHEN, LIANG \& CHEN $^{11}$, LANCY et al. ${ }^{19}$, NAYYAR et al. ${ }^{25}$ e CIESCO et al. ${ }^{12}$ ), visto que foram diferentes os métodos de avaliação. A acuidade de muitos destes outros métodos é bastante questionável, mesmo que tenham sido utilizadas formas indiretas para se avaliar a precisão dos troquéis; por exemplo, ao se usar uma peça fundida para cada troquel, o respectivo processo de usinagem (ajuste) da referida peça fundida é de caráter extremamente variável e subjetivo, fator este fortemente influente e de controle extremamente difícil. Assim, mais à frente, os resultados do presente trabalho serão comparados apenas aos de trabalhos que utilizaram método semelhante ao aqui empregado.

A escolha da espessura de $0,2 \mathrm{~mm}$ para o material de moldagem foi alicerçada nos princípios básicos de polimerização. Na ocorrência desse fenômeno, as moléculas aproximam-se umas das outras, quando de sua união, assim ocorrendo a formação de cadeias e a conseqüente diminuição de volume, inerente a este processo. Sendo assim, o elastômero sofrerá esta contração em direção às paredes internas do casquete, aonde aquele estará aderido pelo adesivo de moldeira, ou por alguma forma de retenção mecânica ou ainda por uma combinação de ambos estes artifícios. Seguindo este raciocínio, pode ser admitido que quanto menor for a espessura do material de moldagem, menor será sua contração volumétrica, e por conseqüente menor será a anomalia criada no molde, como foi citado inclusive por ANUSAVISE ${ }^{2}$, ARAÚJO \& JØRGENSEN ${ }^{3}$, ASGAR ${ }^{4}$, EAMES et al. ${ }^{16}$, SILVA ${ }^{31}$, SAITO \& FREITAS $^{29}$, VIANNA \& FREITAS $^{38}$, entre outros. Porém, em relação ao elastômero, espessuras menores que 0,2 mm talvez não sejam interessantes, apesar de factíveis, visto que a espessura do adesivo de moldeira (principalmente aqueles mais espessos) muitas vezes 
já começa a se aproximar deste índice, assim ocupando o espaço que deveria estar reservado para o material de moldagem.

Na grande maioria dos trabalhos em que foi utilizado o dispositivo de moldagem aqui empregado (ou algum similar seu) também foi usado um microscópio de profundidade, o qual servia para mensurar os eventuais desníveis entre a coroa-padrão e o troquel. Foi constatado que este método era também adequado, quando foram encontrados os mesmos valores numéricos de desajuste da coroa-padrão, para vários troquéis de gessos, medidos tanto com o microscópio comparador, operado por uma pessoa experiente neste método de trabalho, como com o relógio micrométrico aqui utilizado.

\section{2 - Acerca dos resultados aqui obtidos}

Em todos os troquéis de gesso do presente trabalho, a coroa-padrão sempre apresentou-se mais alta, o que pode ser entendido como eles tendo sempre sido maiores do que a estrutura originalmente moldada, levado em consideração o já relatado aspecto das distorções presentes. Tal comportamento também foi encontrado em outros trabalhos, nos quais também foi utilizada a técnica do casquete, como os de GOMES de SÁ, FREITAS \& MARCHESE ${ }^{17}$, MANTOVANI $^{21}$, MARCHESE $^{22}$ e MARCHESE ${ }^{23}$, entre outros.

Os troquéis pertencentes ao grupo U0/R0 apresentaram-se dentre os dimensionalmente melhores (desajuste médio de 80,75 $\mu \mathrm{m}$ ), o que parece ser um resultado bastante lógico e por isso mesmo esperado. Entretanto, os troquéis do grupo U1 mostraram-se tão bons $(114,25 \mu \mathrm{m})$ quanto os do grupo anteriormente citado, o que foi estatisticamente confirmado; este foi um resultado interessante, pois indica que o vazamento do gesso no molde pode ser protelado por até 1 hora, sem perda de qualidade do troquel de gesso assim obtido, desde que obviamente mantidas as demais condições aqui estabelecidas.

O reaproveitamento de um molde, quer após 1 hora (grupo R1, com 153,98 $\mu \mathrm{m}$ ) ou após 2 horas (grupo R2, com 184,54 $\mu \mathrm{m}$ ), conduziu a resultados estatisticamente 
piores que os dos grupo U0/R0., o que já era esperado por já ter sido relatado no trabalho de SILVA ${ }^{31}$.

O pior desempenho foi aquele apresentado pelos troquéis do grupo U2 (com 323,36 $\mu \mathrm{m}$ ), onde o único vazamento do gesso ocorreu quando o molde tinha a idade de 2 horas. Parece surpreendente que este grupo tenha apresentado um comportamento pior até mesmo do que o do grupo onde ocorreu reaproveitamento do molde, fato este que também foi comprovado estatisticamente. Sem sombra de dúvidas, a provável explicação da causa deste último fato é complexa.

No caso do molde onde o gesso foi vazado após 2 horas (grupo U2), uma hipótese aparentemente válida para o fato do troquel ter apresentado as maiores dimensões seria que a polimerização do elastômero teria continuado a ocorrer, até o momento do vazamento, sem a interferência de nenhum outro fator. No caso do molde reaproveitado, R2, onde o vazamento também ocorreu quando o molde tinha a idade de 2 horas, mas cujo troquel apresentou fidelidade aceitável, talvez a água contida no gesso (por ocasião do primeiro e do segundo vazamento) tenha atuado (de alguma forma) como um fato inibidor da referida progressão da polimerização. 
Conclusões 


\section{7- Conclusões}

Após o tratamento estatístico dos resultados encontrados nas condições do presente trabalho, quanto à fidelidade morfo-dimensional dos troquéis de gesso obtidos, foi possível concluir que:

1 - Todos os troquéis, de todos os grupos, apresentaram-se sempre maiores do que a estrutura original moldada;

2 - O melhor resultado ocorreu nos grupos R0/U0 e U1, com desajustes médios respectivamente de 80,75 e 114,25 micrometros;

3 - Os grupos R1 e R2 apresentaram resultados semelhantes entre si (porém piores que os dos grupos R0/U0 e U1), com desajustes médios respectivamente de 153,98 e 184,54 micrometros, e

4 - O pior resultado ocorreu no grupo U2, com um desajuste médio de 323,36 micrometros. 
Referências

Bibliográficas 


\section{Referências Bibliográficas ${ }^{1}$}

1. AMERICAN DENTAL ASSOCIATION. Council on Dental Materials and Devices. Specification $\mathrm{n}^{\circ} 19$ for non-aqueous, elastometric dental impression materials. J. Amer. Dent. Ass., v.94, n.4, p.73341, Apr. 1977.

2. ANUSAVISE K.J. Materiais de moldagem elastoméricos não-aquosos. In: Phillips Materiais Dentários. 10.ed. Rio de Janeiro, Guanabara Koogan, c1998. Cap. 7, p.83-106.

3. ARAÚJO, P.A.; JØRGENSEN, K.D. Effect of material bulk and undercuts on the accuracy of impression materials. J. prosth. Dent., v.54, n.6, p.791-4, Dec. 1985.

4. ASGAR, K. Elastic impression materials. Dent. Clin. N. Amer., v.15, n.1, p.81-98, Jan. 1971.

5. BAYLEY, L.R. Acrylic resin tray for rubber base impression materials. J. prosth. Dent., v.5, n.5, p.658-65, Sep. 1955.

6. BELL, J.W.; VON FRAUNHOFER, J.A. von. The handling of elastomeric impression materials: a review. J Dent, v.3, n.5, p.22937, Sep. 1975.

7. BRADEN, M.; CAUSTON, B.; CLARKE, R. L. A polyether impression rubber. J. Dent. Res., v.51, n.4, p.889-96, July/Aug. 1972.

8. CALOMENI, A.A. A wash technique using rubber-base impression material. J prosth. Dent, v.25, n.5, p.520-4, May 1971.

9. CANNISTRACI, A.J. A new approach to impression taking for crown and bridge. Dent. Clin. North. Am., v.9, n.3, p.33-42, Mar. 1965.

10. CHAI, J.; TAN, E.; PANG, I. A study of surface hardness and dimensional stability of several intermaxillary registration materials. Int. J. Prosthod. v.7, n.6, p.538-42, Nov./Dec. 1994.

\footnotetext{
${ }^{1}$ Normas recomendadas para uso no âmbito da Universidade de São Paulo, com base no documento "Referências Bibliográficas: exemplos", emanado do Conselho Supervisor do Sistema Integrado de Bibliotecas da USP, em reunião de 20 de setembro de 1990.
} 
11. CHEN, S.Y.; LIANG, W.M.; CHEN, F.N. Factors affecting the accuracy of elastomeric impression materials. J Dent, v.32, n.8, p.603-9, Nov. 2004.

12. CIESCO, J.M.S. et al. Comparision of elastomeric impression materials used in fixed prosthodontics. J prosth Dent, v.45, n.1, p.89-94, Jan. 1981.

13. CLANCY, J.M.S.; SCANDRETT, F.R.; ETTINGER, R.L. Long-term dimensional stability of three current elastomers. J. oral Rehabil., v.10, n.4, p.325-33, July 1983.

14. CORSO, M. et al. The effect of temperature changes on the dimensional stability of polyvinyl siloxane and polyether impression materials. J. prosth. Dent., v.79, n.6, p.626-31, June 1998.

15. EAMES, W.B. et al. Elastomeric impression materials: effect of bulk on accuracy. J. prosth. Dent., v.41, n.3, p.304-7, Mar. 1979.

16. EAMES, W.B. et al. Accuracy and dimensional stability of alastomeric impression materials J prosth Dent, v.42, n.2, p.159-62, Aug. 1979.

17. GOMES de SÁ, A.T.; FREITAS, C.A.; MARCHESE, M.P. Fidelidade de troqueis de gesso, obtidos a partir de um tipo silicona de condensação, com três diferentes espessuras, utilizando casquetes de resina acrílica. Rev. Fac. Odont. Lins, v.13, n.2, p.64-8, jul./dez. 2001.

18. GOMES de SÁ, A.T. Influência do casquete (com e sem contato cervical com a estrutura moldada) e da moldeira de estoque, para um único elastômero, sobre a precisão dimensional de troquéis de um gesso tipo IV. Bauru, 2003, 67p. Dissertação (Mestrado) - Faculdade de Odontologia de Bauru, Universidade de São Paulo.

19. LANCY, A.M. et al. Time-dependent accuracy of elastomer impression materials. Part II: polyether, polysulfdes, and polyvinysiloxane. J. prosth. Dent., v.45, n.3, p.329-33, Mar. 1981. 
20. LEFF, A. An improved temporary acrylic fixed bridge. J. prosth. Dent., v.3, n.2, p.245-9, Mar. 1953.

21. MANTOVANI, R.S. Fidelidade morfo-dimensional de troqueis de 2 diferentes gessos tipo IV (Durone ${ }^{\circledR}$ e Vel-Mix $\left.{ }^{\circledR}\right)$, obtido a partir de uma silicona de condensação (Oranwash $\left.{ }^{\circledR}\right)$, usando a técnica do casquete. Bauru, 2001, 82p. Dissertação (Mestrado) Faculdade de Odontologia de Bauru, Universidade de São Paulo.

22. MARCHESE, M.P. Dois métodos de avaliação da fidelidade morfodimensional de troqueis de gesso, obtidos a partir de moldes de elastômeros, com ou sem reaquecimento. Bauru, 1994, 129p. Dissertação (Mestrado) - Faculdade de Odontologia de Bauru, Universidade de São Paulo.

23. MARCHESE, M.P. Fidelidade de troqueis de gesso, obtidos a partir de moldes de vários elastômeros, através de duas diferentes técnicas de moldagem. Bauru, 1999, 162p. Tese (Doutorado) Faculdade de Odontologia de Bauru, Universidade de São Paulo.

24. MARCINAK, C.F. et al. Linear dimensional changes in elastic impression materials. J. Dent. Res. v.59, n.7, p.1152-5, July 1980.

25. NAYYAR, A. et al. Comparison of some properties of polyether and polysulfide materilas. J. prosth. Dent. v.42, n.2, p.163-7, Aug. 1979.

26. PAGNIANO, R.P. et al. Linear dimensional change of acrilic resins used in the fabrication of custom trays. J. prosth. Dent., v. 47, n.3, p.279-83, Mar. 1982.

27. PIWOWARCZYK, A. et al. In vitro study on dimensional accuracy of selected materials for monophase elastic impression making. Int. J. Prosthodont., v.15, n.2, p.168-74, Mar./Apr. 2002.

28. PURK, J.H. et al. The effects of different storage conditions on polyether and polyvinylsiloxane impressions. J. Amer. Dent. Assoc. v.129, n.7, p.1014-21, July 1998.

29. SAITO, M.H.; FREITAS, C.A. Avaliação da fidelidade morfodimensional de troqueis de gesso Vel-Mix obtidos a partir de 
moldes de silicona de condensação (Optosil/ Xantopren), com diferentes níveis de "alívios”. In: JORNADA ODONTOLÓGICA DE BAURU “PROF. CARLOS EDUARDO FRANCISCHONE”, 12., Bauru, 1999. Anais. Bauru, FOB-USP, 1999. p.104.

30. SCHELB, E. et al. Compatibility of type IV dental stones with polyether impression materials. J. prosth. Dent., v.60, n.5, p. 540-2, Nov. 1988.

31. SILVA, R.G. Fidelidade morfo-dimensional de troquéis confeccionados com gesso tipo IV (Vel-Mix $\left.{ }^{\circledR}\right)$, obtidos a partir de uma silicona de condensação (Oranwash $\left.{ }^{\circledR}\right)$, usando a técnica do casquete, com três vazamentos subseqüentes após a confecção do molde: relatório final de Bolsa de Iniciação Científica concedida pela FAPESP. Bauru, FOB - USP, 2002. (processo 00/14749-3).

32. SOARES, J.C.F.; MONDELLI, J. Avaliação do reembasamento na moldagem com resina acrílica gelada. Rev. Facul. Odotol. Bauru, v.8, n.1/2, p.23-9, Jan./Jun. 2000.

33. STACKHOUSE Jr. J.A. The accuracy of stone dies made from rubber impression materials. J. prosth. Dent., v.24, n.4, p.377-86, Oct. 1970.

34. TAN, E.; CHAI, J.; WOZNIAK, W.T. Working times of elastomeric impression materials according to dimensional stability and detail reproduction. Int. J. Prosthod. v.8, n.8, p.541-7, Nov./Dec. 1995.

35. TOSTI, A. Elastic impressions using custom acrylic trays. Dent. Diag., v.75, n.3, p.94-7, Mar. 1969.

36. VALDERHAUG, J.; FLØYSTRAND, F. Dimensional stability of elastomeric impression materials in custom-made and stocks trays.

J. prosth. Dent., v.52, n.4, p.514-7, Oct. 1984.

37. VALLE, A.L. Avaliação do desajuste cervical de coroas totais fundidas a partir de moldagens obtidas com moldeira e casquete individual, utilizando três tipos de materiais à base de borracha. 
Bauru, 1978. 91 p. Tese (Doutorado) - Faculdade de Odontologia de Bauru, Universidade de São Paulo.

38. VIANNA, L.S.; FREITAS, C.A. Fidelidade morfo-dimensional de troqueis de gesso (Vel-Mix) confeccionados em moldes de uma silicona de condensação (Zetaplus/Oranwash), com diferentes níveis de alívios. In: SIMPÓSIO DE INICIAÇÃO CIENTÍFICA DA UNIVERSIDADE DE SÃO PAULO - SICUSP, 6., Ribeirão Preto, 1998. Anais. São Paulo, USP, 1998. p.209. 


$$
\text { Abstract }
$$




\section{Abstract}

\section{Evaluation of the accuracy of stone dies obtained from a polyether mould (through shell tecnique) and made by pouring in different times or by successive pourings in a same mould.}

The accuracy of moulds obtained through shell technique from a polyether (Impregum Soft) was indirectly evaluated, by direct evaluation of the accuracy of stone dies. A standard crown (extremely well fitted to the standard die, both presenting their oclusal portions at the same level) was used to verify the height difference between itself and each obtained Vel-Mix stone die. The condition of stone pouring lend to the name of 5 groups; some moulds were utilized (U) just once time to make a die at 3 different ages, in order to conform respectively groups UO (pouring immediately after its obtention), U1 (1 hour later) and U2 (2 hours later); the others moulds were reutilized $(\mathrm{R})$, in order to conform the groups R1 (reutilized 1 hour after pouring by first time) and R2 (reutilized 2 hours after that first pouring); by analogy, the group UO could also be named RO. To quantify the referred height differences, in micrometers, a depth microscope was used. The ideal result (ideal acuraccy) would be the inexistence of such differences. Statistically treated data allowed to conclude that 1) in all groups, stone dies were allways bigger than the standard die; 2) best results were presented by specimens of groups UO/RO and U1, respectively with height difference of 80,75 and 114.25 micrometers, but without statistically significant difference; 3) groups R1 and R2, worse than the aforementioned, presented a similar performance, respectively with 153.98 and 184.54 micrometers, and 5) worse desajust was detected in group U2, with 323.36 micrometers. 